
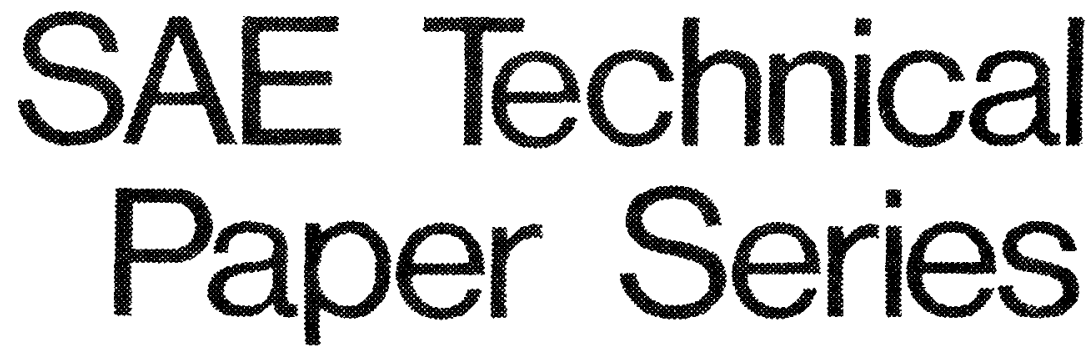

830567

\title{
Motor Vehicle Forward Lighting
}

\author{
Michael Perel, Paul L. OIson, \\ Michael Sivak and Jere W. Medlin, Jr.
}




\section{Motor Vehicle Forward Lighting}

MOTOR VEHICLE FORWARD LIGHTING

\section{ABSTRACT}

This paper surveys the literature on motor vehicle headlighting and its influence on the ability of drivers to avoid accidents. The review identifies the key relationships between headlamp design characteristics and driver and environmental factors. The major safety problems associated with headlighting are discussed, and issues needing the attention of the research community are identified.

THE NIGHTTIME ACCIDENT RATE IS OVER THREE TIMES THE DAY RATE. Many factors $c$ an be blamed for this difference including alcohol, young reckless drivers, and fatique. It is also reasonable to assume that the poor visual environment at $n$ ight $c$ an affect safety since so much of the information required by drivers is obtained visually.

There are a number of major differences between the visual environment at night and day that can make night driving a difficult task. At night, the broad fields of view of daylight narrow to the region illuminated by artificial lighting--headlights or fixed road lighting. At night, objects are seen under lower contrasts and non-uniform illumination, which makes detection difficult. As ambient light decreases, colors fade, shadows disappear, resolution is lowered, and object detail vanishes. Peripheral vision is reduced, causing the driver to modify search and scan behavior. Increased glare causes eye strain and fatigue and further increases the difficulty of detecting hazardous objects. Various aspects of the highway environment $c$ an further degrade driver vision at night. The variation in pavement reflectivity from asphalt to concrete $c$ an affect the contrast and, hence, detectability of potential

\author{
Michael Perel, Paul L. Olson,
Michael Sivak and Jere W. Medlin, Jr. \\ Michael Perel, Paul L. Olson,
Michael Sivak and Jere W. Medlin, Jr. \\ Michael Perel, Paul L. OIson,
Michael Sivak and Jere W. Medlin, Jr.
}

hazards. Adverse weather can reduce visibility distances in many circumstances. In fog, backscatter from headlamps increases glare and reduces the ability of headlights to illuminate road delineation and other critical objects. In rain, the specular reflectance of light from roadways makes it virtually impossible for drivers to see lane markings.

Not all drivers are affected to the same degree by the nighttime visual environment. For example, drivers with various visual deficiencies can be more sensitive to nighttime driving problems. Some of the visual characteristics wich can reduce drivers' visual performance at night include glare resistance, contrast sensitivity, peripheral acuity, and night myopia. Drivers who are fatigued are more adversely affected by the nighttime visual environment because of changes in their visual search behavior and even lower sensitivity to peripheral cues. The use of alcohol and other drugs can impair driver visual information processing and make night driving more dangerous.

Vehicle characteristics can also play a role in influencing the nighttime visual environment. Headiamps are the primary source of illumination for drivers on unlighted roads. The design goal of headlamps is to illuminate the roadway and potential hazards without subjecting oncoming drivers to excessive glare. There are a number of headlamp design characteristics which can influence driver vision and, hence, capability to avoid accidents, including beam pattern, intensity, and lamp construction. The performance that headlamps are designed to achieve $c$ an be degraded by misaim, dirt, lamp outage, and incorrect voltage.

In order to identify the major problems in headlighting, the above driver, vehicle, and environmental factors were examined in a review of the literature to determine their frequency of occurrence, their relation to crashes, and their relation to oriver performance. The 
review also describes the historical development of the design of headlighting and tries to identify the safety-related rationale for the various engineering developments and standard requirements.

Most of the review focuses on data from laboratory and field tests and computer models. Very little information exists describing the exposure characteristics of drivers, the relation of the $h$ ?adlamp characteristics to accidents, and the rationale for headlamp development over the years. Where possible, the relation of headlamp desian to safety was determined through the use of the proxy measures that have been used in lab, field; and computer modeling studies. These relationships show the sensitivity of safety-related performance to variations in headlamp characteristics. The factors, such as driver and environmental characteristics that interact with headlamp design to affect performance were also examined. The goal of examining all the above types of data was to determine the nature and extent of the hazards associated with headlight factors and the extent to which modifications to headlamp characteristics or their interacting factors could lead to improved driver performance. One problem area that became ciear at the outset of the review was the need to improve performance of the low beam rather than high beam. This need arises from two basic reasons. First, most night driving is on low beam because of the high traffic densities that are encountered. Second, high beam intensities have reached the point of diminishing returns beyond which no significant increases in seeing distance could be gained without extremely high levels of intensity. Thus, the majority of the review will focus on low beam.

\section{REVIEW OF PERTINENT ACCIDENT EXPERIENCE}

VISIBILITY - If the great bulk of information necessary for the safe and effective operation of a motor vehicle is acquired visually, and if darkness impairs vision, then lighting systems which improve vision ought to have an effect on safety. Researchers have been more successful in correlating accident rates with fixed illumination systems characteristics than headlighting. The reason is that controlled studies are easier to run with fixed illumination systems than headlights. There are thousands of miles of roads illuminated at different levels. Lighting systems are being installed where none existed, and old systems are being upgraded somewhere at almost any time. Sometimes it is even possible to alter the lighting levels on a particular street and study the effects.

There are several good summaries of this research. One of the better is provided by Gallagher and Janoff $(1)^{\star}$. The results of these studies are quite variable. Among the reasons are that changes in lighting levels were frequentiy confounded with changes in traffic volume, upgraded enforcement

activities, or other roadway modifications. In some cases accident rates actually increased with illumination levels. But, the general trend is toward fewer accidents as illumination levels increase. Two examples will be offered for purposes of illustration.

One of the better recent studies is by Scott (2). He looked at the relationship of eight variables to accidents at 41 sites in Great Britain. Average road surface luminance gave the best correlation and it could not be improved by the addition of other variables. Scott's data are surmarized in Figure 1, and show that the proportion of accidents during hours of darkness dropped in a relatively linear fashion as the level of illumination increased.

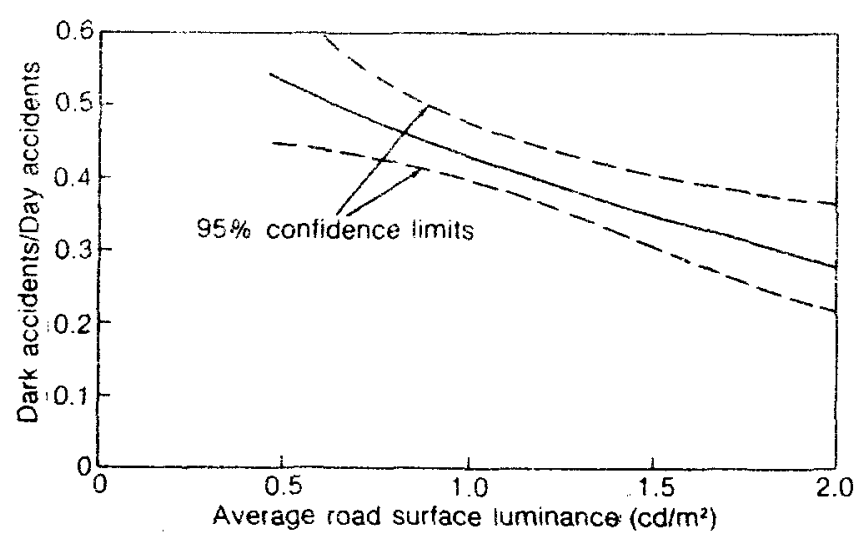

Fig. 1 - Best fitted relationship between Dark/Day accidents and average road surface luminance (2)

Another recent and very interesting analysis has been reported by Merritt et al. (3). Using data from the 1977 Fatal Accident Reporting System (FARS) developed by the National Highway Traffic Safety Administration (NHTSA), they compared the ratio of single-vehicle fatal accidents on straight and curved road sections under three lighting conditions: daylight, night but lighted and night not lighted. An update of this analys is using 1980 FARS data is reproduced in Table $i$. The percentages in the first two colums [i.e., daylight and night (but lighted)] are strikingly similar. However, the proportion occurring on curves is higher on unlighted roads at night, as shown in the third column. These data suggest that improved lighting helps to reduce accidents on curves.

$\star$ Numbers in parentheses designate References at end of paper 
TABLE 1 - Summary of 1980 Accident Statistics Relating To Lighting Conditions, Road Geometry, and Run-Off Road Accidents

\begin{tabular}{|c|c|c|c|c|c|c|}
\hline & \multicolumn{6}{|c|}{$\begin{array}{l}\text { SINGLE VEHICLE FATAL ACCIDENTS } \\
\text { AS A FUNCTION OF LIGHTING AND ROAD GEOMETRY }\end{array}$} \\
\hline & DAY & LIGHT & NIGHT (BUT & LIGHTEO) & NIGHT & (DARK) \\
\hline $\begin{array}{l}\text { Straight } \\
\text { and Level }\end{array}$ & 5454 & $(67 x)$ & 3009 & $(64 x)$ & 6758 & (58*) \\
\hline $\begin{array}{l}\text { Curved } \\
\text { and Leve. }\end{array}$ & 2693 & (336) & 1662 & $(36 x)$ & 4876 & $(42 x)$ \\
\hline Totais & 8147 & $(100)$ & 4671 & $(100 x)$ & 11634 & $(1006)$ \\
\hline $\begin{array}{l}\text { Straight } \\
\text { and Grade }\end{array}$ & 2137 & $(464)$ & 714 & $(458)$ & 2329 & $(39 x)$ \\
\hline $\begin{array}{l}\text { Curved } \\
\text { and Grade }\end{array}$ & 2539 & $(55 x)$ & 873 & $(55 x)$ & 3575 & $(618)$ \\
\hline Totals & 4676 & $(100 x)$ & 1587 & $(1006)$ & 5904 & $(100 x)$ \\
\hline $\begin{array}{l}\text { All Straight } \\
\text { (Level + Grade) }\end{array}$ & 7591 & (59k) & 3723 & $(59 \%)$ & 9087 & $(52 x)$ \\
\hline $\begin{array}{l}\text { A1l Curved } \\
\text { (Level + Grade) }\end{array}$ & 5232 & $(418)$ & 2535 & $(416)$ & 8451 & $(48 x)$ \\
\hline Totals & 12823 & $(100 x)$ & 6258 & $(1006)$ & 17538 & $(1006)$ \\
\hline
\end{tabular}

It seems clear that better roadway lighting reduces accidents at night. But, does this hold true for headlighting as well? Unfortunately, there is no direct evidence that it does. The problem is that the various conditions mentioned earlier that made it relatively easy to run controlled studies of fixed lighting have no parallels in headlighting.

The best evidence for headlighting as a factor in accidents comes from in-depth studies. For example, the Tri-Level study carried out at Indiana University (4) found that improved forward light ing would have been of at least possible benefit in about $3 \%$ of the accidents studied. However, there are problems with the in-depth approach that may tend to work against variables such as lighting. For example, a single-vehicle, run-off-the-road crash may be ascribed to driving too fast or poor delineation. However, better lichting might have provided the operator with sufficient information to properly adjust his or her speed or see where the road was going despite poor delineation. In short, unless the operator ran into something because of lack of visibility, inadequate headlighting could be a contributory factor that is easily overlooked.

Another assessment of the potential role of headlighting in accidents was presented by Hale and Blomberg (5). They estimated the percent of pedestrian and bicycle accidents where poor visibility could have been a causal factor. Since improved headlighting is one approach to increase visibility, their estimates provide upper bounds on the headlighting problem. Using data from in-depth accident investigation studies, they calculated that from $3-23 \%$ of all pedestrian accidents were attributable to poor visibility. The range for bicycle accidents is 23-32\%. The large variability in these estimates is due in part to the difficulty of judging the role of visibility in accidents.

GLARE - If glare reduces the ability to see, then glare should cause accidents. Some evidence that it does is provided by Burger et al. (6), who used a critical incident approach to identify vehicle driver mismatch problems contributing to accidents or near accidents. Based on 3,500 survey returns, citing nearly 1,700 accidents or near accidents, the authors conclude that glare from the headiamps of oncoming vehicles is the single most important driver-vehicle mismatch problem to which NHTSA should direct its attention.

What does not become clear from these data is whether the glare problem is caused by failure to dim, misaim, or inadequate low beam design. Clearly, the solution recommended depends very much on the source of the problem. In sum, the two attributes most important in headlamp design, illumination and glare, both seem to relate to the probability of accidents. What we do not have is the relationship of various levels of headlight illumination and glare to accidents. Further, the difficulties of acquiring such information are such that it is unlikely to be available in the foreseeable future. In lieu of accident data, researchers must rely on surrogate criteria such as visibility distance to evaluate the problem of nighttime visibility.

WEATHER - Adverse weather can make the relatively poor visual conditions at night even worse. However, there is only limited information on the relation between headlighting, adverse weather, and accidents. Koth et al. (7) reviewed data from a number of studies of fog and accidents. The conclusions of this review were that nighttime increases the incidence of fog accidents. The scope of fog accidents is minor, representing about 2 or $3 \%$ of all accidents, but the severity of fog accidents can be great.

Rain can increase glare and affect the contrast of critical objects illuminated by headlamps. Accidents in rain were investigated by Haghighi-Talab (8) and reviewed in an OECD report (9). The results of these studies indicate that the degrading effects of rainfall on vision contribute to accident causation.

None of the studies of adverse weather were able to associate headlamp design with accident rates. However, the influence of headlamp design on visibility in adverse weather is an important factor that should be considered in headlamp evaluations.

REVIEW OF EXPOSURE AND OTHER EXPERIENCES OF THE DRIVING PUBLIC

The seriousness of the night driving safety problems is demonstrated in part by the poor performance of drivers in being able to stop safely, read signs, and follow the road path. It is also a function of the exposure of 
drivers to the more hazardous lamp design characteristics and environmental conditions. Another component of the night driving hazard is the extent to which driver limitations can reduce the seeing distance provided by headlamps. Unfortunately, there is only limited data on the exposure characteristics of the night driving environment and the range of capabilities of the driving population. VEHICLE AND LAMP CHARACTERISTICS - A considerable number of vehicle and lamp characteristics affecting night driving performance vary from car to car. These include beam intensity, beam pattern, beam color, aim, lamp mounting height, driver eye height, lens and reflector deterioration, windshield tint, dirt, inoperative lamps, and lamp voltage.

Beam intensity and pattern, although regulated by FMVSS 108, can vary significantly from manufacturer to manufacturer. FMVSS 108 references $S A E$ photometric requirements, which set maximum and/or minimum intensity values for a limited number of points in the beam pattern. The permissible range of values for some of the test points can be relatively large. Thus, a variety of beam patterns and intensities $c$ an be designed to meet the standard. The quality control employed in the manufacturing process can also affect variation from lamp to 1 amp.

Most U.S. vehicles use sealed beam lamps which are basically similar in terms of intensity pattern. Intensity levels do vary from lamp to lamp. However, no systematic survey of this variability has been published. A small selection of tungsten sealed beam lamps was examined by Bhise el al. (10), who found variations in maximum output as great as two to one.

Motorcycles can use European non-sealed headlamps with a "sharp cut-off" heam pattern. It is not known how many "sharp cut-off" lamps are currently in use in the U.S.

In recent years the frequency of use of halogen sealed beams has increased. One reason for the advent of halogen sealed beams is to take advantage of the raised maximum intensity now permitted on high beam by Federal standards. No published data has been found which reports the actual intensities of halogen high or low beams. Also no information on the percent of cars equipped with halogen lamps was found.

The halogen lamps operate at higher filament temperatures and hence emit a whiter light than tungsten units. The effect of such color differénces on safety are nil although some drivers have the impression that they can see better with the whiter light. In France, headlamps are yellow, a policy based on the assumption that it reduces glare. Yellow headlamps (other than fog lights) are illegal in the U.S. In Europe the lamp color issue has been extensively researched $(11,12,13)$. The findings indicate that if there is any benefit to yellow headlamps, it is slight. These benefits must be balanced against certain disadvantages, such as a slight loss in seeing distance, and change in apparent color of roadside objects.

Lamp mounting height and driver eye height in cars have been decreasing since the 1950's as car manufacturers have sought to change the looks of their cars. In the early 1950's lamp height was about 32 inches. Currently the minimum mounting height is 24 inches measured to the center of the lamp. For reasons of international harmonization and improved aerodyriamics some proposals have suggested that the height be slightly lowered even further. Driver eye heights in cars have also dropped over the last 30 years, from about 3.95 feet to 3.5 feet (for the $15 \mathrm{th}$ percentile) (14). Although there are many drivers in vans, pickups, and trucks with higher eye heights, the exposure of drivers with low eye heights is the critical factor determining the degree of glare hazard.

Misaim and dirt on lamps are encountered rather frequently by drivers. They are discussed more fully in a later section of the report.

Lens and reflector deterioration of glass sealed beam lamps is practically non-existent. A very limited number of plastic headlamps have been introduced and drivers may encounter some lens abrasion depending on the quality of the protective coating and the harshness of the environment.

Defects, whether in-operative lamps or lamps operated at less than design voltage are a problem of unknown size. The Ford Motor Company in their comments to the NHTSA estimated that $51.9 \mathrm{milli}$ ion headlamps were replaced on passenger cars in the U.S. in 1979, of which $63 \%$ were due to burnout. It is not known how many nighttime miles are travelled with one lamp out before it is replaced. With halogen lamps, sealed or unsealed, it is possible for a driver to use them even if the lens has cracked. Under this condition moisture and dirt can enter the lamp and reduce the road illumination.

Drivers have also been exposed to visibility degradation at night because of the increased use of tinting on windshields. Not on ly do more cars use tinted glass, but the transmissivity has decreased over the last 30 years. The estimated percent of cars with tinted windshields is about $80 \%$. Light transmittance through a tinted windshield can be as 10 as $65 \%$ depending on installation angle, compared to $82-84 \%$ transmittance for a non-t int windscreen.

ENVIRONMENTAL CHARACTERISTICS - The nature of the roadway enviroment to which drivers are exposed also affects night driving safety and the performance of headlamps. Environmental factors include weather, roadway design, and critical object visual characteristics.

The weather under which drivers must operate varies from region to region. A summary of weather patterns has been prepared 
by Thomas and reported by 01 son et al. (15). These data show that the incidence of fog yaries from practically never in much of the country to 10 to $20 \%$ of the days in coastal areas. The incidence of precipitation of 0.01 inch or more varies from 20 to 50 days in the Southwest, to 100 to 150 days in the Central and Eastern regions, to 150 to 170 days in the far Northwest and around the Great Lakes. Bhise et al. (10) estimated that the typical U.S. driver will encounter 91 days of driving annually with precipitation greater than 0.01 inch. Thus, adverse weather cannot be ignored in evaluations of headlamps performance. The distribution of artificial illumination has been reported by Bhise et al. (10) and is reproduced in Table 2. These data show that artificial illumination is rare on rural roads. This suggests that most high-speed driving is done using only headlamp illumination.

TABLE 2 - Frequency of Fixed Roadway Lighting on U.S. Roads (10)

\begin{tabular}{|c|c|c|c|c|}
\hline \multirow[b]{2}{*}{ Road Type } & \multicolumn{3}{|c|}{ ENY IRONMENT } & $-\ldots$. \\
\hline & $\begin{array}{l}\text { sillu- } \\
\text { minated }\end{array}$ & $\begin{array}{l}\text { Not } \\
\text { 1) Numinated }\end{array}$ & $\begin{array}{l}\text { Illu- } \\
\text { minated }\end{array}$ & $\begin{array}{l}\text { Not } \\
111 \text { uminated }\end{array}$ \\
\hline $\begin{array}{l}\text { Interstate } \\
\text { System }\end{array}$ & 6.0 & 94.0 & 91.1 & 8.9 \\
\hline $\begin{array}{l}\text { All o: her } \\
\text { Freeways }\end{array}$ & 5.3 & 94.7 & 85.5 & 14.5 \\
\hline $\begin{array}{l}\text { Sivided Roads } \\
\text { (Nonfreeways) }\end{array}$ & 7.9 & 92.1 & 87.8 & 12.2 \\
\hline $\begin{array}{l}\text { Undivided Roads } \\
\text { (Over } 2 \text { Lanes) }\end{array}$ & 0.9 & 99.1 & 87.8 & 12.2 \\
\hline $\begin{array}{l}\text { Undivided Roads } \\
\text { (? lanes) }\end{array}$ & 2.5 & 97.5 & 55.2 & 44.8 \\
\hline
\end{tabular}

Obstacles on the road must be brighter or darker than their background in order to be detected. The reflectivity of pavements, that often form the background for objects of concern to drivers, has seldom been measured accurately. Some data have been provided by Bhise et a . (10) and are reproduced in Figure 2. These data should be compared with those in Figure 3, also from Bhise et al. (10). Clearly, much clothing has reflective characteristics similar to road pavements that might constitute a background in a potential collision situation. Thus, low contrasts between targets and background are common when the target is a pedestrian.

The exposure of drivers to hills and curves $c$ an also influence headlamp performance. A beam pattern that provides good visibility distance under straight, flat road conditions, may produce too much glare to oncoming drivers on curves or hills. A survey of road topography was performed by Bhise et a 1. (10) and incorporated in the Ford headlamp evaluation model, which is discussed later in the paper.

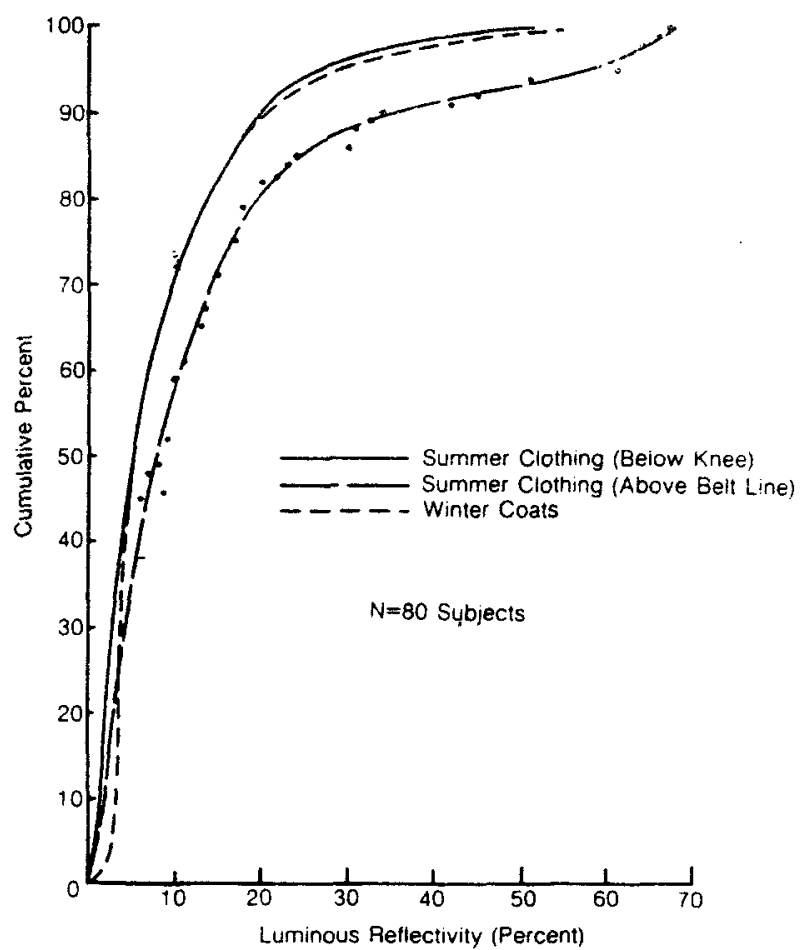

Fig. 2 - Cumulative distribution of pedestrian clothing reflectance (10)

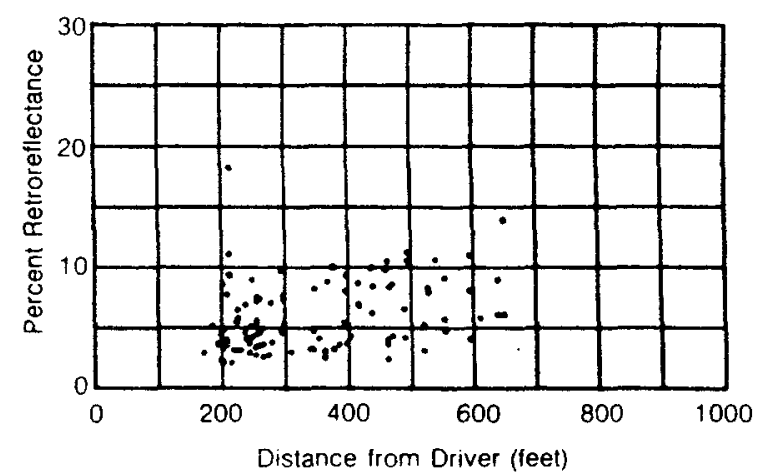

Fig. 3 - Measured pavement retroreflectivity characteristics (10)

In summary, the above types of factors form the environment under which headlamps must provide visibility to drivers. Driver safety $c$ an be reduced if headlamp design does not take these environmental factors into account.

DRIVER CHARACTERISTICS - A number of driver related factors $c$ an affect the visibility provided by headlamps. These characteristics include vision, fatigue, alertness, and alcohol. The distribution of these characteristics in the driving population and their effect on headlamp performance is only partially known. 
A number of visual deficiencies can affect how well drivers can see at night. These include glare sensitivity, lens yellowing, contrast sensitivity, and acuity. The degree to which these factors can vary from individual to individual can be significant. They have a) so been shown to vary with age.

One source of information on the variation on drivers' response to glare is by Pulling et a). (16). They measured the headlight glare resistance of 30 subjects in a driving simulator. They increased the intensity of simulated oncoming headlights until the subject slowed down or otherwise gave evidence of being impaired. The headlight glare resistance was measured as the logarithm of the ratio, at the thresholo for glare acceptability, between the illuminarce from orcoming headiights and the ambient illumination. The results are shown in Figure 4. A smali scale survey was also conducted to assess the log glare ratios fount in typical driving envirnnments. These. measurements showed giare ratios as much as $50: 1$ (10y=1.7) on residental streets and over $500: 1(10 \mathrm{~g}=2.7)$ on an unlighted interstate highway. Comparing these values to the headlight glare resistance suggests that increasing age can nave a significant impact on the ability of drivers to drive under many typical night conditions.

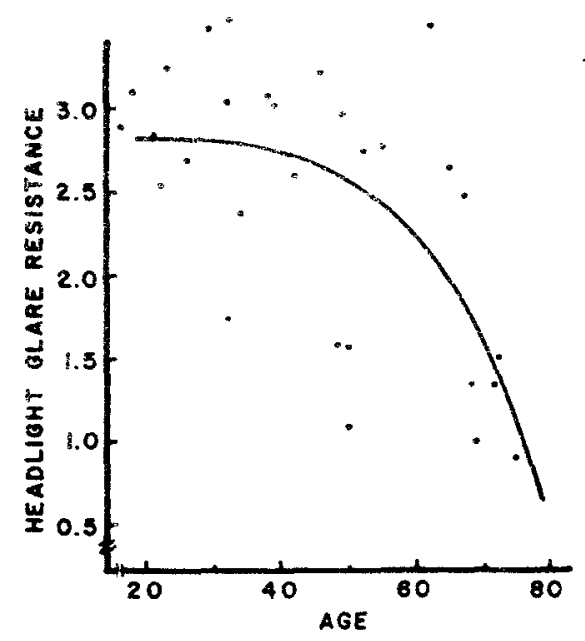

Fig. 4 - Headlight glare resistance vs. age (16)

Another indication of the variability of driver visual capabilities with age is shown in a study by Sturgis and 0sgnod (17). Figure 5 fron that study shers how visual acuity decreases as luminance is reduced and as age increases.

of the many other factors that can influence driver performance, such as fatigue and alertness, little is known about their frequency of occurrence in the population.

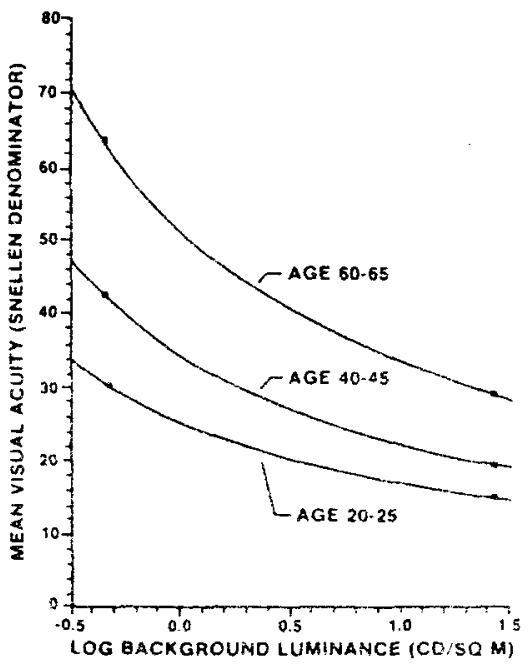

Fig. 5 - Effect of background luminance on visual acuity of three age groups (17)

Considerable information does exist about the alcohol levels of the driving population. Blood alcohol concentration levels vary depending on time and day of the week, reaching a peak in the early morning hours of weekends. At such times, one driver in eight may have a blood alcohol level of $.10 \%$ or more (18).

\section{ENG INEERING DEVELOPMENT AND TESTING}

BACKGROUND - Headlamps, like many vehicle components, have evolved over a long period of time. The history of this process has been reviewed by a number of authors $(19,20,21$, $22,23,24)$. A brief summary is presented here. HEADLIGHTING IN THE UNITED STATES -

Headlights first appeared about 1906. The first headlights used acetylene and, like the first electric lamps which became available later, had a "beam pattern" much like a search light. About the time of World War I, an effort was made to more adequately iliuminate the road by molding prisms into the lenses. Further developments continued in the 1920's and early $1930^{\prime} \mathrm{s}$, resulting in substantial improvements in light distribution intensity. Unfortunately, this era was also characterized by a proliferation of beam patterns, lamp sizes and shapes that not only made headlamp components expensive, but also made them difficult to replace when necessary. In the middle 1930's work began toward the development of the sealed beam, which was introduced on 1940 model cars. The sealed beam is probably the most significant single development ever to occur in headlighting. It solved some serious problems associated with aging of the lamp unit, virtually guaranteeing consistent, good quality headlighting throughout the life of the vehicle. Headlamps were also standardized dimensionally as well, making them readily available at relatively low cost. 
Since the introduction of the sealed beam, some rather significant changes have been introduced to solve certain problems and improve performance. For example, it was felt that performance of the early lamps in rain, snow and fog was not as good as it might have been, due to illumination scattered above horizontal. In 1955 this scatter was reduced by the addition of a "fog cap" (a metal shield positioned near the filament).

Visual aiming of sealed beams was found to be very difficult, due to the lack of well-defined edges in the pattern. This problem was aided greatly by the introduction of mechanically aimable units in 1956.

In 1957 the first four-lamp system was introduced. By partially separating high and low-beam functions, the need for compromise in lens design was reduced. Although in theory the four-lamp system was developed to provide drivers with better illumination, no published research studies predating 1957 have been found that evaluated the visibility benefits of this system.

Further refinements in design resulted in an improved two-lamp system in 1959. Again, no controlled experimental studies have been found that evaluated the visibility performance of this development.

The 1970's saw the introduction of rectangular two-and four-lamp systems. The primary benefit was in styling and the fact that they would permit better utilization of the space on the front of the vehicle.

Halogen technology was not applied to sealed beams until the late 1970 's. The major reason for this development was that FMVSS 108 had been changed to allow a more powerful high beam (from 75,000 cd to $150,000 \mathrm{~cd}$ ), with the limitation that power consumption had to stay the same. The low beam of these units have to meet the same photometric requirements as their tungsten counterparts.

HEADLIGHTING IN EUROPE - European

headlighting systems are based on the development of the Graves "anti-dazzle" bulb, which was patented in 1920. The Graves bulb provides a simple and inexpensive way of greatly reducing the amount of light projected above horizontal. A metal shield surrounds the front, sides and bottom of the low beam filament, preventing any light from being projected directly forward or to the lower portion of the reflector. While this reduces the efficiency of the lamp in terms of luminous flux/watt compared to the sealed beam system, it does produce significantly less glare.

In 1953-54 a number of lighting tests were carried out under the auspices of the CIE (International Commission on Illumination). These tests have been described by de Boer (25, 26) and Jones (27). As part of this program, comparisons were made between American and European lighting systems. The results suggested that visibility distances on the left side of the road were comparable under most conditions tested. However, since the American low beam was asymmetrical (i.e., it directed the most intense portion of the beam to the right), it produced greater visibility distances on the right side of the road. As a result, it was recommended that changes be made to the Graves shield to allow a greater amount of light to be projected along the right edge of the road. This was accomplished by removing a portion of the shield on one side. The sharp cut-off characteristic was retained. However, instead of presenting a symmetrical appearance when projected against a wall of screen, it now appeared flat on the left with a 15 degree upward slant on the right. This revised concept became the European standard.

More recent ly a further modification has taken place, with the high intensity portions above horizontal being cut of $f$ at +1 degree. This produces a shape approximating the letter "Z," instead of a shallow "v." This change reduces problems with glare on curves and into the rear view mirrors of vehicles ahead. Another advance in European headlighting came with the introduction of iodine (halogen) sources. The first mention of these in the literature occurs in the early 1960's $(28,29)$, although they did not appear on cars until somet ime later.

The use of iodine vapor inside a light bulb makes possible a chemical reaction that causes vaporized tungsten to redeposit on the filament itself rather than on the glass envelope (30). Thus, the problem of bulb blackening is eliminated. It also makes it possible to generate substantially more luminous flux/watt and to use a smaller filament. The smaller filament simplifies the problem of focusing the beam. Because the filament must be run at a much higher temperature in order to operate the chemical reaction just described, it was necessary to use a quartz envelope on the bulb. It is for this reason that such sources are termed quartz-iodine or quartz-halogen.

Substantial development has taken place in the last several years since halogen lamps were first introduced. Earlier versions could use only a single filament in the bulb, making it applicable only for four-lamp systems. Present-day versions incorporate two filaments, so that both high and low beams can be generated from a single source.

One of the major differences between European and U.S. lamps is in construction. European lamps are not hermetically sealed and are typically of composite construction, i.e., a glass lens glued to a metal reflector.

Unsealed and composite lamps can be designed in shapes and sizes that may give them full economy and styling benefits. However, European construction $c$ an lead to two potential problems that the sealed beam does not have: (1) accumulation of dirt and moisture on interior surfaces due to the "breathing" action of such units, and (2) oxidation of the reflector. One of the best surveys of this problem (31) found significant distortion of 
beam patterns in as iittle as six months in a sample of European lamps they tested. European safety inspection data (as quoted by Ehrhardt, 30) have shown serious deterioration as a common reason for failures, but such surveys are unsystematic and do not quantitatively measure lamp performance. The Europeans have worked hard to solve these lamp durability problems, but data on newer headlamp designs are scarce. Although some European lamps may provide good long term performance, the current standards do not set requirements that prevent poorer quality lamps from being sold. For example, they do not specify corrosion performance tests.

Another major difference between European and U.S. headlamps is the method of aim.

European lamps are aimed visually by projecting the beam on a screen directly or on a screen through a condensing lens. Because the European low beam pattern has a relatively sharp intensity gradient, aim can be adjusted by positioning the lamp until the gradient falls in line with the reference markings on the screen. Aiming accuracy depends in part on how precisely the beam pattern can be aligned with the reference markings. Because the U.S. beam pattern does not have intensity gradients as distinctive as those in European lamps, visual aiming is more difficult. Visual aiming is used in the U.S. although it has been shown to be less accurate than mechanical aiming (32). Mechanical aiming checks alignment by reference to the aiming pads built into the headlamp lens. A vertical plane through the surface of these pads forms the aiming plane. Mechanical aimers are used to align the aiming plane vertically and horizontally using spirit levels and a split image/mirror system. This aiming method is not affected by beam pattern intensity gradients.

Questions of aim and durability are becoming increasingly important in the U.S. as the impetus grows to improve aerodynamics and increase styling options. These motivations have been the major force behind the engineering developments that seek to develop new lamp shapes, sizes, aiming devices, construction, and materials. The safety

implications of these possible changes are only beginning to be understood.

Durability may become a problem because

plastic lamps are being proposed. This type of lamp needs a protective coating on the lens to protect it from abrasion. A scratched lens can alter the beam pattern and increase glare to oncoming drivers. The degree to which performance suffers depends on the coating used Durability can also be affected if the reflector materials corrode or the inside of the lamp becomes dirty, which may be more likely if replaceable bulb systems are introduced. Problems with European type systems have been noted above. New materials and techniques used in lamp design can improve this problem but may have other durability problems. In particular, if a lens cracks, drivers may balk at paying the cost of lamp replacement which may be relatively high for limited production lamp shapes. Because, the replaceable bulb will still put light on the road, some drivers may not realize that the cracked lens allows dirt, moisture, and possibly corrosion to reduce lamp performance. Another potential problem with some replaceable bulb systems is that photometrics can become degraded if the filament is not aligned precisely when a new bulb is installed. This problem $c$ an be solved by having precise tolerances for filament position and bulb mounting.

Maintaining correct aim may become more difficult if new lamp designs do not have aiming pads compatible with current mechanical aimers. The quality of aim in the vehicle fleet will thus be dependent on the extent to which service shops purchase and can properly use adapters for these lamps.

The use of headlamp covers is another approach with the potential to improve aerodynamics. Testing of glass covers was conducted by the California Highway Patrol and reported in comments to NHTSA Docket 81-11. Their testing found that the covers reduced maximum low beam intensity from 10-23 percent and increased glare intensity above horizontal. Their conclusion was that the types of covers tested degrade headlamp performance and should be prohibited. Another new development with potential effects on lamp performance is the lowering of passenger car lamp mounting heights. The impetus comes from the desire for international harmonization, since Europe allows a slightly lower mounting height, and the desire to lower hood lines for reduced drag. Over the years minimum headlamp heights have been lowered from 30-32 inches to 24 inches from the ground to the center of the lens. In practice the range of current passenger car headlamp heights is from 24-28 inches. The effect of lowering mounting heights on seeing distance was studied in a test conducted by Roper and Meese (33). Figure 6 shows the results, which apply to lamps meeting SAE specifications for low beam and a target 16 inches square with 7 percent reflectance. These data show that about 10 feet of seeing distance are lost for each inch the lamp height is lowered. This figure can vary, however, depending on such factors as driver eye height, beam aim, and beam pattern.

Changes are also being suggested that have the potential for upgrading low beam photometrics. For example, four lamp systems are being proposed which use filaments parallel to the longitudinal axis and single function low beam units. This development is said to allow higher light output in the lower right quadrant for visibility with the same or less glare intensity in the upper left quadrant as current U.S. low beams. Also, composite lamps with replaceable bulbs are being proposed which could permit lamp designers to develop separate left and right-side beam patterns for improved 
visibility with less glare. Not all the engineering changes claim they will increase seeing distance. Some of the new lamp designs being proposed may be limited in terms of the extent to which their photometrics can be improved although all claim to meet current standards.

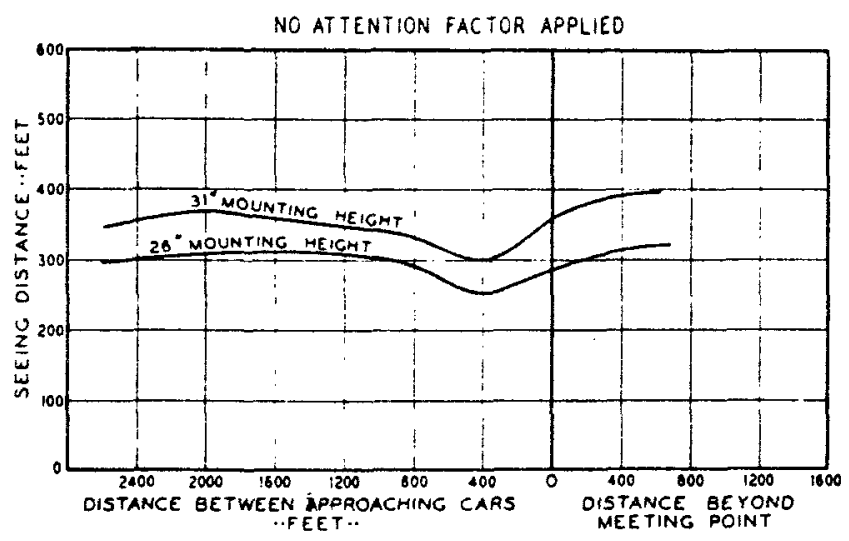

Fig. 6 - Effect of lamp mounting height on visibility distance (33)

MOTORCYCLE HEADLAMPS - The main focus of this report is automobile headlighting. However, a great variety of special lighting systems have been developed for certain applications. Motorcycles are such a case, and are of interest here because they operate in the same environment as automobiles. The special problems to lighting design posed by motorcycle use are:

a. The vehicle rolls and the lamp is steered in cornering, distorting the patterns and changing its illumination distance.

b. There is usually only one lamp.

c. Many bikes (especially smaller ones) have limited electrical power available.

The standards controlling motorcycle lighting are less restrictive than those controlling automobile lighting. As a result there are many varieties of motorcycle headlamps, making them potentially more expensive and difficult to find when a replacement is required. Many of these lamps, especially thcie designed for mid-size and smaller motorcycles, have considerably less output than a car headlamp.

This problem has been explored in detail in two recent NHTSA-sponsored studies (34, 35). Among their findings was that considerable improvement has resulted from the introduction of halogen sealed beams.

ENGINEERING DEVELOPMENT - Lighting development work in the United States has been generally described by Kilgour (23). It is a complex process, often initiated by a single person or company. This is typically followed by laboratory and field testing, using procedures which are standardized on a company, not an industry basis. If modifications to industry standards are sought, the problem moves to an appropriate committee of the Society of Automotive Engineers (SAE). In the case of beam development, hardware is usually fabricated and appropriate demonstrations are staged for committee members. Ultimately, when it appears as though consensus is likely, the issue is balloted to the committee. Some lamp modifications may require changes to Federal Motor Vehicle Safety Standard 108 before they $c$ an be implemented.

While this method of headlamp development is not "scientific" in the usual meaning of the term, it cannot be said to have produced a poor lighting system. However, there is a problem in that the process is not documented in the open literature. This make it difficult to review and critique the rationale for proposed changes and to quantify the improvements in safety that these changes may bring.

\section{LABORATORY AND FIELD TESTING AND COMPUTER MODELING}

In view of the difficulty of relating headlamp design factors to accidents and the 1 imited information on the safety related aspects of engineering developments over the years, the most descriptive and detailed information on headlamp safety problems comes from experimental studies and computer modeling. The dependent variables used in these tests and analytic analyses serve as proxy measures of the degree to which headlamp characteristics can affect night driving safety. VISIBILITY - The most basic function of headlamps is to provide drivers with the visibility for vehicle control, for detection and assimilation of road sign information, as well as detection and identification of roadway hazards (e.g., pedestrians, stalled vehicles, and pot holes). Most headlight visibility research has been concerned with the roadway hazard problem.

One way to evaluate the seriousness of the road hazard problem is to compare vehicle stopping distance to driver seeing distance. If the seeing distance is greater than the stopping distance, then the driver would have a positive safety margin and should be able to avoid hitting the obstacle.

Many studies have been run to determine seeing distances and most have used a somewhat similar methodology. For example, the targets are either small ( 0.5 meter square is typical) or man-size. They are painted a uniform dark gray (e.g., 7\% reflective), or covered with dark-colored fabric. They are typically flat, but are occasionally three-dimensional. The subjects ride in an automobile that is driven at a set speed on a straight, flat road. Subjects are typically under 30 years old, alert, and unfatigued. One or more targets are placed at known positions along the right edge of the road, and a glare source, representing 
an oncoming car, is placed to the left. The subjects are instructed to indicate when each target is detected, usually by pressing a button. The results are reported in terms of mean detection distances for the various conditions of interest. Occasionally, distributional data are provided as well.

Table 3 is a summary listing of

twenty-five headlighting studies that have in common the detection and/or identification of large and/or small, low-contrast targets placed on the right side of the road using standard
U.S. and European headlamps. Most used a methodology similar to that just described (called "standard" in the table). Those that used a different method are briefly described. The differences in visibility distance among studies are impressive. For example, with no opposing glare car, mean visibility distances to a large target range from 14 meters [46.2 feet] (Johansson and Rumar, 45) to 120 meters [396 feet] (Hemion, 43), a difference of about $8.5: 1$.

TABLE 3 - Means (X) And Standard Deviations (sd) of Visibility Distance to Low-Contrast Targets Reported In Twenty-Five Field Studies

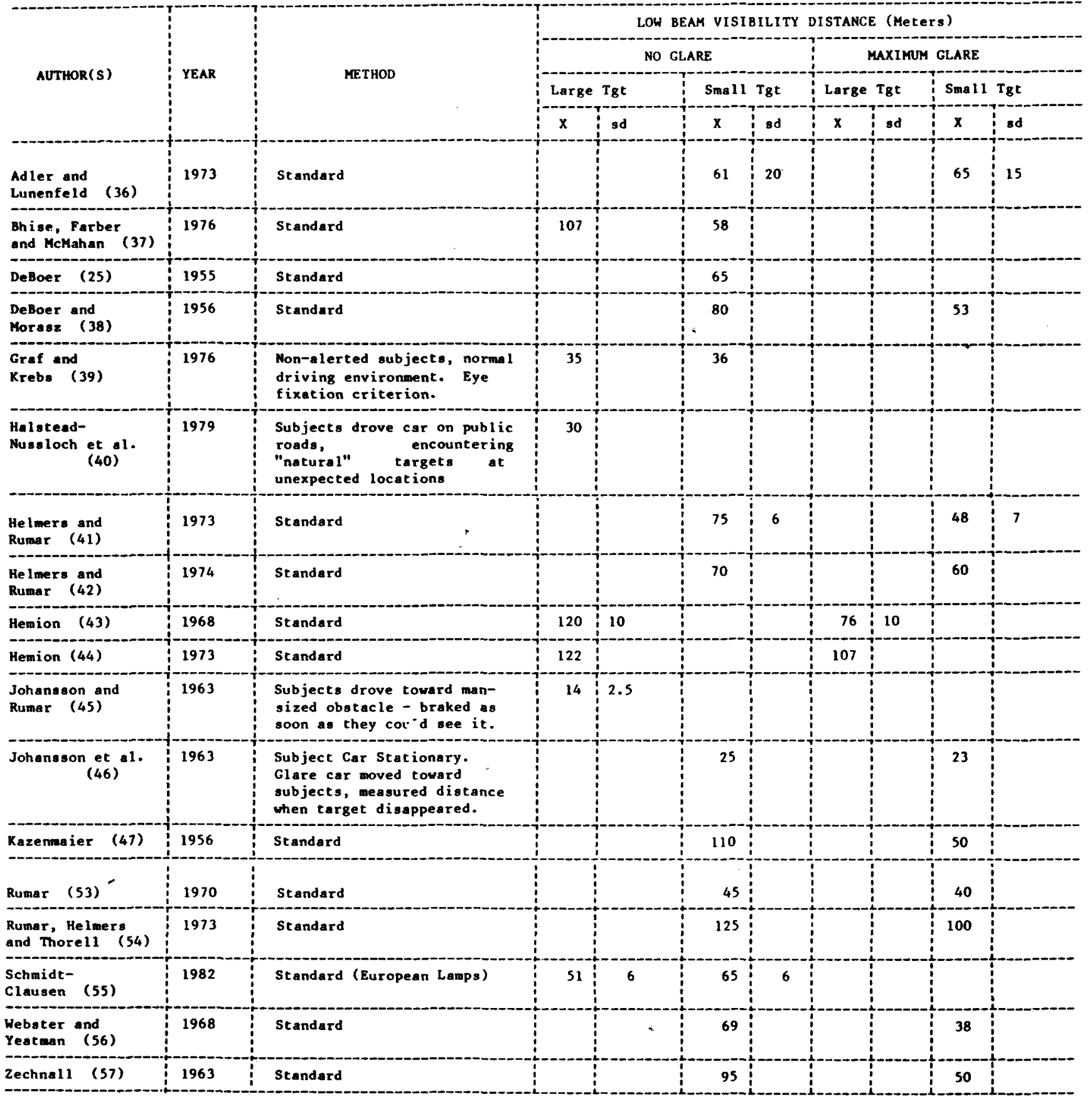


TABLE 3 - (econtinued)

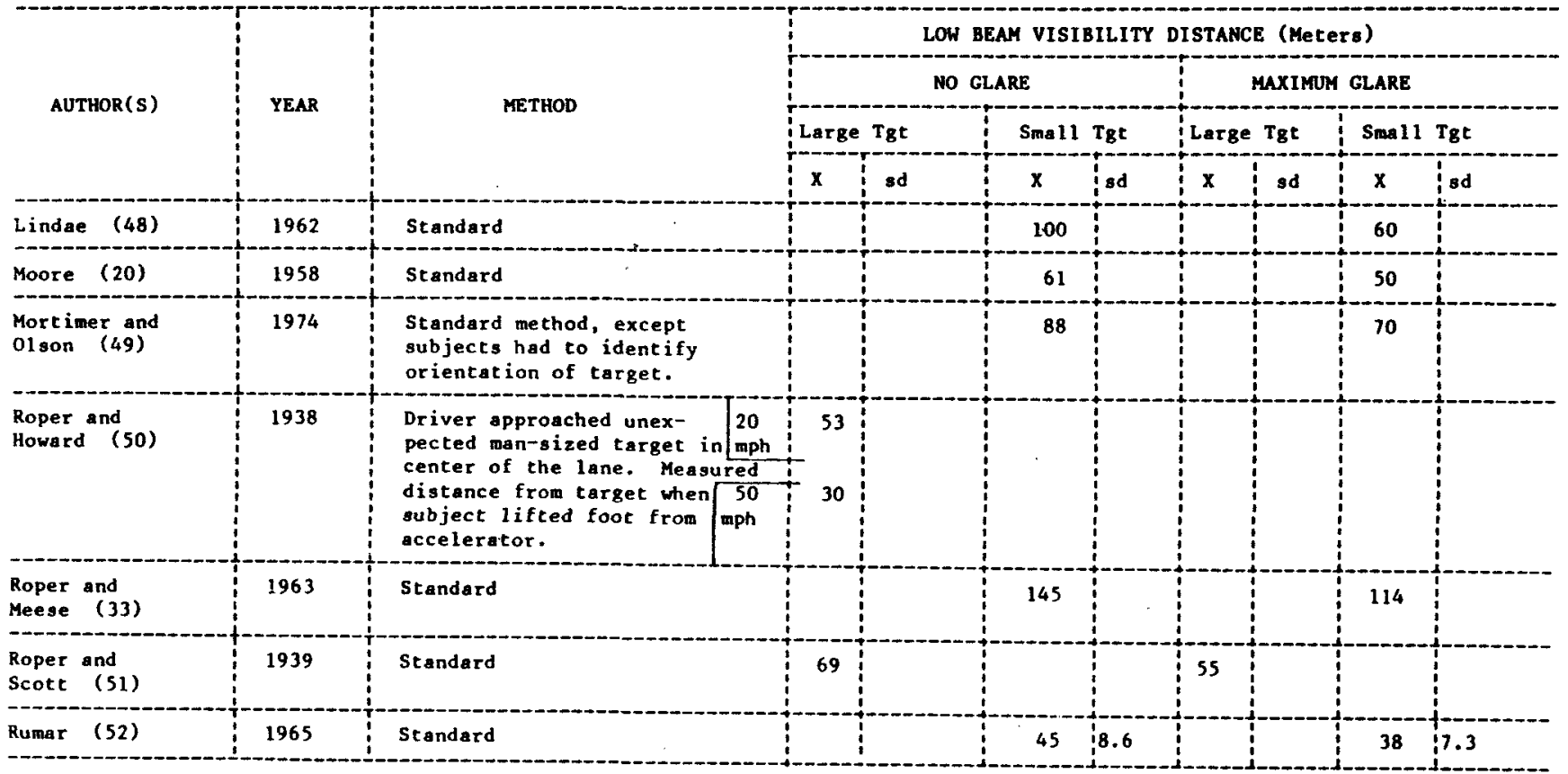

Some of the reasons for these differences in mean visibility distances are known. For example, the studies which report the shortest distances used methods which introduced uncertainty about target position (e.g., Johansson and Rumar. 45), the nature of the target (e.g., Halstead-Nussloch et al., 40), or deceived the subject about the nature of the test in an effort to determine the visibility distance of unalerted subjects (e.g., Roper and Howard, 50; and Graf and Krebs, 39).

In some cases mean visibility distances vary from study to study because the test conditions vary. For example, targets may have different shapes, reflectances and locations. Beam intensities and patterns may vary, and subjects may have different visual capabilities. The ambient lighting and target background may not be the same from study to study. All of these factors can affect the visibility distances measured.

Sometimes the reason for the differences among studies cannot be determined because important information is often omitted. For example, many investigators do not provide photometric data on the headlamps, which is critical because of the manufacturing and design variability from lamp to lamp.

Background reflectivity, which is as important in detection as target reflectivity, is rarely measured.

Campbell (58) has calculated automobile stopping distances for level roads, and braking in the skid mode. Figure 7 shows these calculated stopping distances as a function of initial velocity, two road frictions, and two driver reaction times. These curves $c$ an be considered to be conservative, minimum estimates of stopping distance.
By comparing the range of seeing distances to the estimated stopping distances, the maximum safe speed $c$ an be determined. Because of the variability in both seeing distance and stopping distance, the maximum safe speed can vary from about $20 \mathrm{mph}$ to about $55 \mathrm{mph}$, under optimum conditions without an oncoming glare car. With an opposing glare source seeing distances are less, and maximum safe speeds would be correspondingly lower. Thus, since many of the seeing distances and stopping distances were conservative estimates and did not account for the limit conditions associated with many accidents, one can conclude that under real world conditions many drivers cannot see far enough on low beams to stop and prevent a collision with a roadway hazard.

In order to determine ways to reduce this negative safety margin, researchers have conducted many tests to determine the extent to which various factors increase detection distance. One of the key factors in lamp design that $c$ an be changed to increase visibility distance is beam intensity

BEAM INTENSITY - Data provided by Roper and Howard (50) serve as an illustration of the relationship between beam intensity and visibility distance for three levels of target reflectivity. (See Figure 8.) These data are for a pedestrian target, no opposing glare car, unalerted subjects and car speed of $50 \mathrm{mph}$. As a reference, current U.S. low beams would direct about 18-30,000 candlepower toward a right side target 200 feet down the road; high beams, about 60,000 to 120,000 .

The data indicates that gains in visibility distance associated with increasing lamp output are relatively rapid up to 25,000 candlepower, and flatten out considerably after 


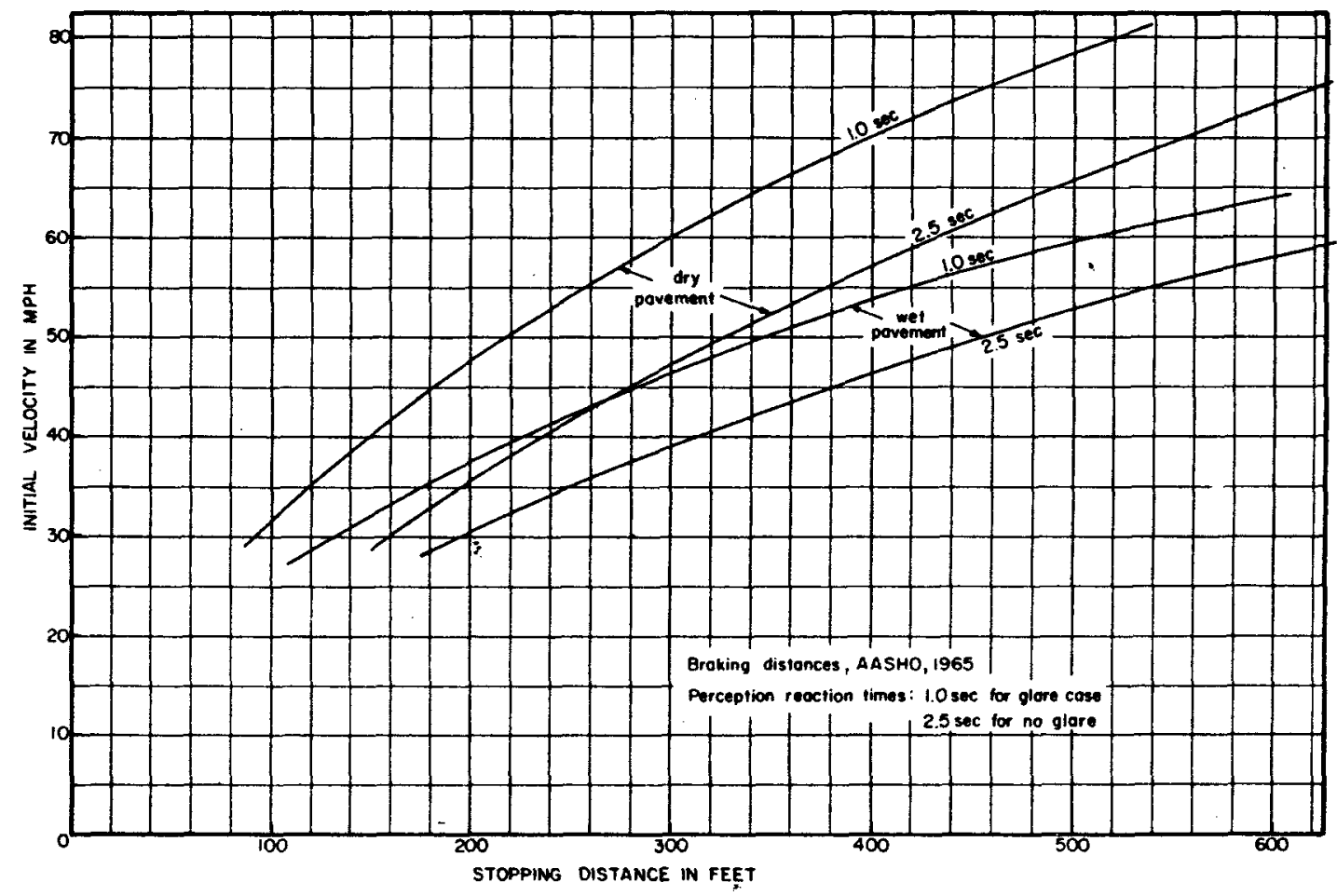

Fig. 7 - Automobile stopping distances

(58)

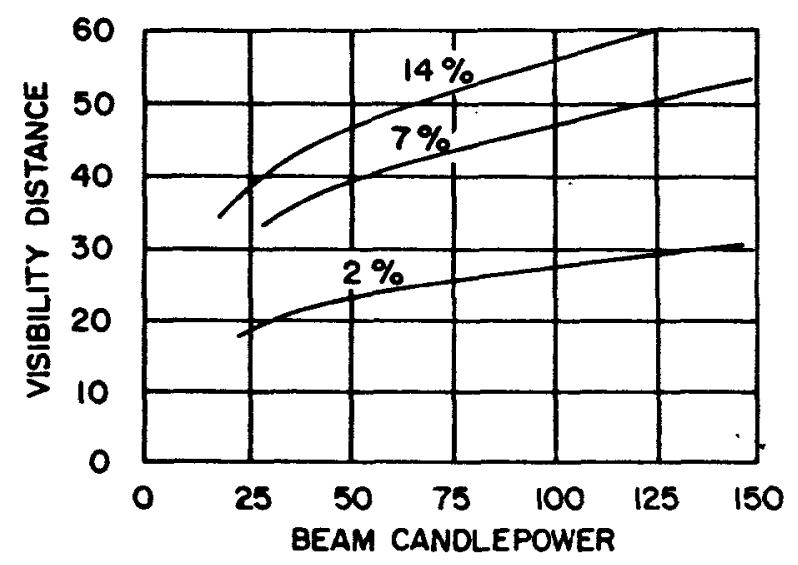

Fig. 8 - Visibility distance as a function of beam candlepower and target reflectivity (50)

(Candlepower values are $\times 1,000$ )

(Visibility distances are $\times 10$ feet)

that. Obviously, it is not easy to obtain great improvéments in seeing distance over what is provided today simply by using more powerful lamps, even ignoring the problem of glare. For example, the recent increase in output allowed for high heams (from $75,000 \mathrm{~cd}$ to $150,000 \mathrm{~cd}$ max.) resulted in about a $20 \%$ improvement in visibility distance, according to Figure 8 . Some of the reasons for the relatively poor gain in visibility per unit increase in intensity are as follows:
First, illumination reaching a surface varies as the square of the distance from the source. That is, the illumination reaching a surface is equal to the luminous intensity of the source directed toward that surface divided by the square of the distance. This means, for example, that to double the distance between a source and surface yet maintain the latter at the same level of illumination, the source intensity will have to be increased fourfold. Second, the key to target detection is not simply target luminance, but the contrast provide by the target and its background. Typically, the headlamps are illuminating both surfaces. If the source is moved further away, but its output is increased to provide the same target luminance, contrast will actually decrease because the background is now relatively closer to the target. Thus, if the target was at threshold before, it becomes sub-threshold under the revised conditions. Required threshold contrast varies inversely with level of illumination, so the only solution is to increase source intensity further to a point where the reduced contrast will be at threshold again.

Third, the atmosphere has a significant scattering effect. Except for extreme conditions such as fog, this problem has largely been ignored unt il recentiy. However, measurements reported by Huculak (59) show that atmospheric scattering can be quite significant. Huculak of fers one example in which the retroreflectance of the road surface 
at about 200 meters appeared to be $50 \%$ higher than it actually was, due to atmospheric scatter. And this was reported to be a clear night. What this means is that if we use more powerful lamps to try to see further, atmospheric scattering works against us by reducing the contrast of more distant targets.

In sum, a great deal of evidence about visibility leads to the following conclusions:

a. When considering low-contrast targets such as dark-clad pedestrians, animals and unlighted vehicles, present-day low beams headlights do not offer sufficient visibility for safe operation at the national limit ( 55 mph or about $90 \mathrm{~km} / \mathrm{hr}$ ). There is some debate about the degree of shortfall, but under real world conditions the maximum safe speed is probably no higher than $70 \mathrm{~km} / \mathrm{hr}$ (45 mph).

b. The output of present-day low beam headlamps is at the point that large increases in visibility distances require very great increases in intensity. The main restriction to further increases is glare.

GLARE CONTROL - In the presence of oncoming vehicle glare, visibility distance can be reduced significantly compared to open road driving. Table 3 previously shown, lists the seeing distances with oncoming vehicles under maximum glare conditions and shows the reduction in distance compared to the no glare condition. The negative safety margin for unopposed driving is even lower in the presence of oncoming traffic. Glare that reduces visibility distance is called disability giare. Glare can also have the effect of causing discomfort to the driver without reducing visibility. This is called discomfort or psychological glare. If low beam intensity could be increased without increasing glare, then seeing distance could be increased, at least a little. Efforts to improve seeing distance by controlling glare have concentrated on beam pattern shaping and polarized headlighting.

The major beam patterns that have been studied and compared have been the U.S. tungsten sealed beam pattern and the European sharp cut-off pattern. There is no clear evidence that one pattern is any better than the other. The results depend on the circumstances under which the beams were evaluated, the evaluation criteria selected, and the particular lamps that were chosen to be representative of the beam pattern. For example, U.S. lamps typically show higher seeing distances for right side targets; European beams because of their reduced giare show longer seeing distances for left side targets. Furthermore, a beam pattern with a sharp intensity gradient like the European beam that may provide good performance on flat straight roads, may not provide as good a visibility distance on curves, hills, and with less than perfect aim. Another caution to note in making such comparisons is that the seeing distances were usually measured with the glare lamps the same as the visibility lamps. Different results would be obtained if unlike beams were used. Thus, the driver of a car with European lamps meeting a car with U.S. low beams might not have seeing distances as good as the opposing driver using a U.S. beam.

Because of the difficulty of substantially improving seeing distance with conventional systems, polarized headlighting was

investigated in a number of studies. In this system polarized filters are placed in front of the headlamps and in front of the driver's eyes. The axes of polarization are oriented so that when the driver looks through the filter, light from the opposing lamps is blocked out. Because of the significant glare reduction possible with the system, it permits extreme lamp intensities and reduces the need for high standards of aim and maintenance. However, because of concerns over cost and proper use of the system by drivers, it was never implemented. Another approach to lengthen seeing distance through beam pattern changes, was the three-beam system. The third beam was designed to increase seeing distance in certain meeting situations. One study found that target detection distance was extended 29 percent further in two-lane meeting situations than standard low beams. (60). However, the midbeam was too bright to be used in meetings on curves and following closely or overtaking and passing preceeding cars. Because of concern over proper driver use of the beams and the criticality of proper aim for the mid beam lamp, this system was never implemented. Ongoing research at the Unversity of Michigan is investigating whether more conventional approaches to low beam pattern design can result in increases in seeing distance in meeting situations. The extent of the increase possible depends on the limitations imposed by discomfort and disability glare.

DISABILITY GLARE - Light entering the eye is to some extent scattered by the optic media so that random illumination is superimposed over the image of both target and background. As a result, background luminance is effectively increased and contrast is reduced (61). The effect has been shown to be the same as that produced by supplying veiling luminance directly over the target and background $(62$, 63).

A systematic evaluation of the relationship between illuminating and glaring intensities and seeing distance has been provided by Grime (64). His data are reproduced in Figure 9. To provide a frame of reference, present U.S. low beams, in the situation described for Figure 9, would produce about 18-30,000 cd of illumination towards a right side target $200 \mathrm{feet}$ down the road and about $1500 \mathrm{~cd}$ or less of glare towards an opposing car ahout ?00 feet away. 


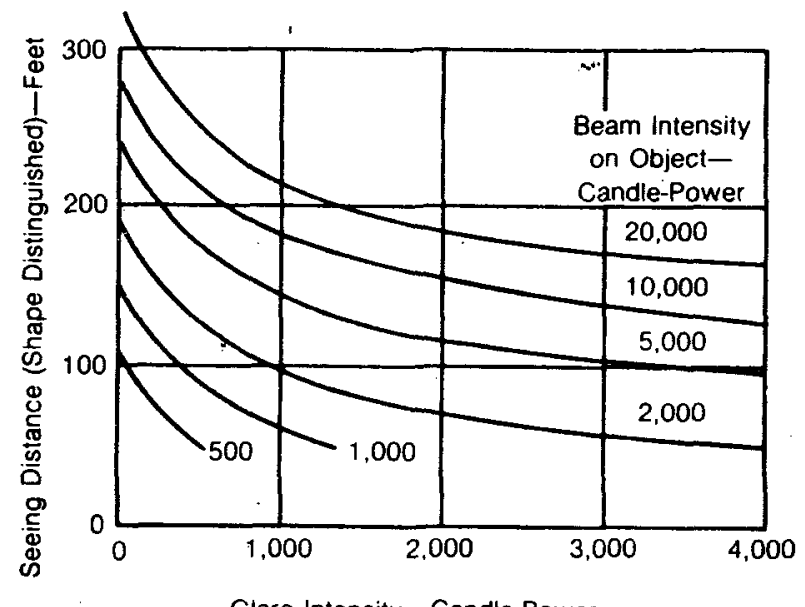

Glare Intensity - Candle-Power

Fig. 9 - The relation between seeing distance, beam intensity directed at an object and glaring intensity (64) [Object position 10 feet to side of opposing lamp and 10 feet behind it; object reflectance, 7 percent; height of object, 18 inches; car speed, $30 \mathrm{mph}$ ]

The main point from Figure 9 is that the disabling effects of glare are non-linear. Low levels of glare produce more degradation per unit increase than higher levels.

Extrapolating from the relationships shown in this figure indicate that doubling current low beam intensity towards the target increases seeing distance by about the same percentage as reducing glare by $50 \%$. The advantage of reducing glare is that discomfort is reduced. However, this approach requires a very sharp intensity gradient that may be difficult to achieve in practice. The European beam patterns ire designed to produce lower glare but in doing so they sacrifice intensity towards roadside objects and also lamp efficiency. The U.S. sealed beams rely on lens prescription changes to control the beam patterns but this approach cannot produce sharp intensity gradients. Hence, glare levels cannot be easily reduced without lowering overall output.

There are also problems with the approach of increasing intensity to increase seeing distance. The effects of glare as represented in Figure 9 assume straight, flat road meeting situations. Because of misaim and various road geometries, the eyes of oncoming drivers are sometimes exposed to portions of the beam other than the "design" glare zone. Being hit suddenly with the high intensity portion of the low beam pattern when cresting a hill or rounding a curve is an unpleasant experience at best. It can lead to severe, if brief, losses in visibility. More intense lights would exacerbate this problem.

The solution to these seemingly irreconcilable tradeoffs may be to selectively increase intensity in the direction of hazards on the right side of the road. Glare intensities directed at oncoming drivers may need to be raised slightly if conventional sealed beam technology is used. However, new technology (e.g., single-function, axial-filament low beams) may allow glare intensities to be lowered. The key to determining how much intensity can be selectively increased is the discomfort glare acceptable to drivers.

Discomfort Glare. It is common knowledge that glaring lights can produce a sensation of discomfort. While the sensation is real enough, the mechanism(s) involved are not known. Lacking an understanding of what physical responses are involved, it has been necessary to approach discomfort glare as a problem in subjective scaling.

Most headlight discomfort evaluations have employed the following 9-point scale described by DeBoer (1965):
1. unbearable
2.
3. disturbing
4.
5. just acceptable
6.
7. satisfactory
8.
9. just noticeable

The DeBoer scale has been used by a number of different investigators. Of special interest is the meticulous laboratory work reported by Schmidt-Clausen and Bindels (66). Their results are reproduced in Figure 10 . Based on these data, the peak glaring intensities of U.S. low beams in a meet on a straight-flat road would be rated about "4," suggesting that a further increase in glare is undesirable. Some verification of this was obtained by Bhise et al. (10), based on a dimming request study. Their results are reproduced in Figure 11 , and show that requests for dimming began increasing rapidly when the glare experienced by the opposing driver was such as to produce a rating of "4" or less. Mortimer and 01 son (67) also used the DeBoer scale to obtain glare ratings for several lighting systems in a full-scale meeting situation. Their data are reproduced in Figure 12. The considerable effect of glare angle, as determined by where the subjects were searching for targets, should be noted. The data also suggest that ratings obtained in a realistic meeting situation may be different from those derived from laboratory studies. Assuming the driver chooses to look ahead or to the right rather than at the approaching headlamps, it appears that U.S. low beams could be rated " 5 " or better, rather than the "4" predicted by the DeBoer equation.

$A$ problem with ratings of the type described has been pointed out by Lulla and Bennett $(68)$. They note that the scale values assigned a given glare level depend to some 


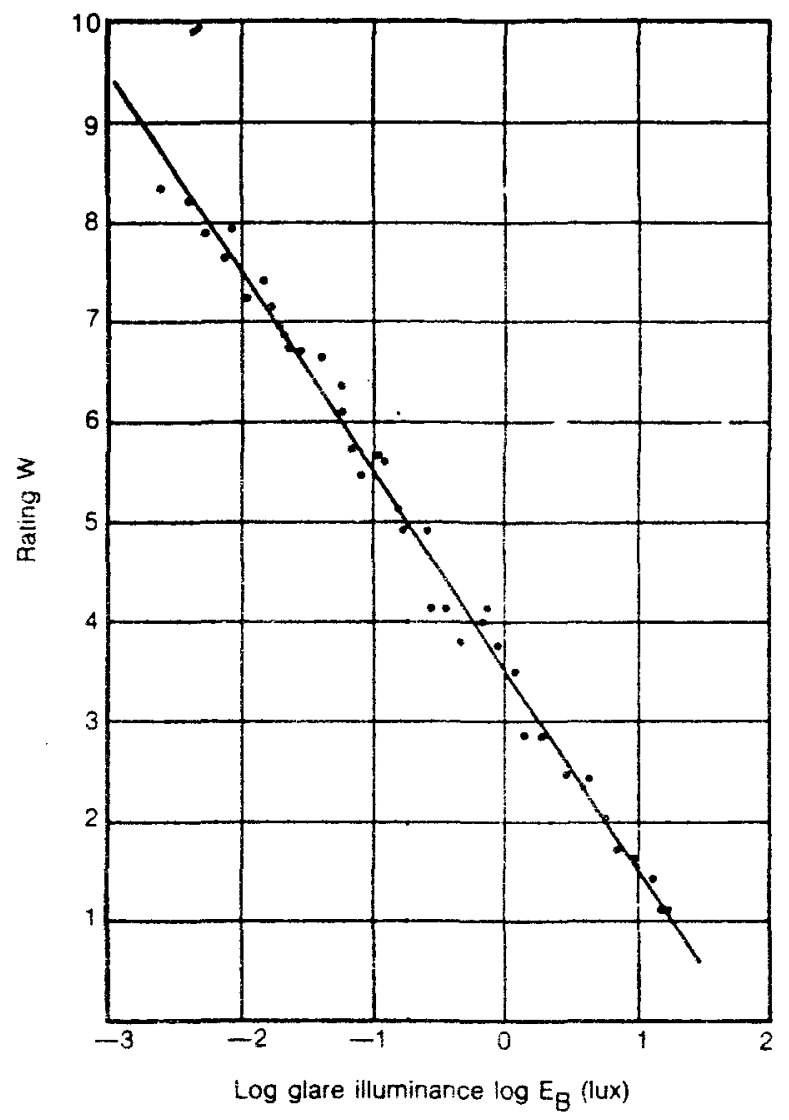

Fig. 10 - DeBoer ratings $(W)$ as a function of glare illuminance (66)

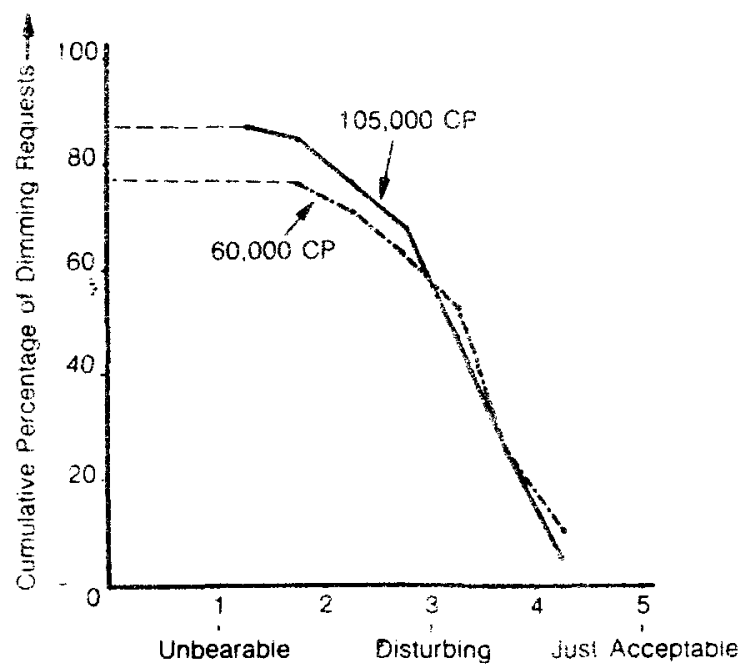

Discomfort Glare index (W)

Fig. 11 - Request for dimming from approaching drivers as a function of calculated glare discomfort rating (10)

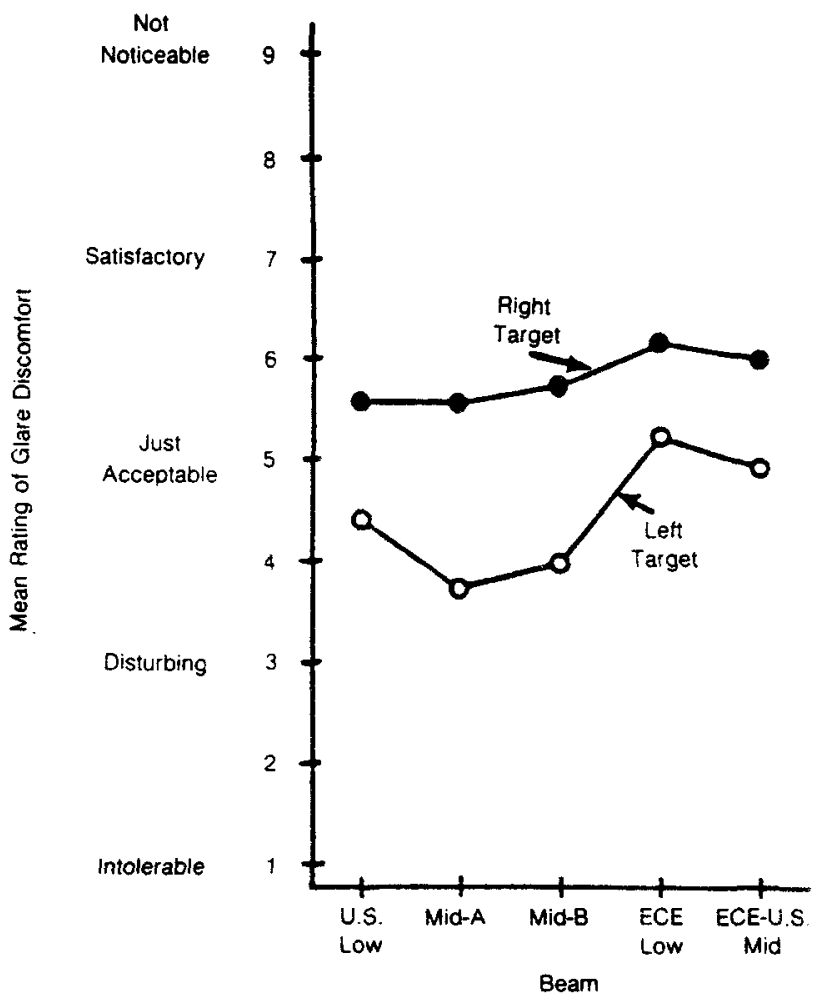

Fig. 12 - Mean ratings of maximum glare discomfort in meetings with five beams when searching for targets on the right and left side of the lane (67)

extent on the range of stimuli presented. This suggests that: (1) the ratings cannot be treated as absolutes, and (2) if the composition of glare to which people are exposed in everyday driving changes, their judgment of what is "just acceptable" will change as well. Some additional work on this phenomenon is currently being carried out at the University of Michigan.

This work was carried out in two stages. Stage 1 was a laboratory study very much like that of Schmidt-Clausen and Bindels. The results were identical. Stage 2 used the laboratory approach and rating scale, but was carried out in on a roadway with automobiles. The stage 2 results are shown in Figure 13. It is apparent from Figure 13 that the subjects in the field setting rated the same glare levels more comfortable than did the subjects in the laboratory setting (DeBoer prediction).

Discomfort glare is one of the principal limiting factors in attempting to gain improved visibility by increasing lamp output. There are only a few rigorous studies of discomfort glare in a setting applicable to headlighting. 


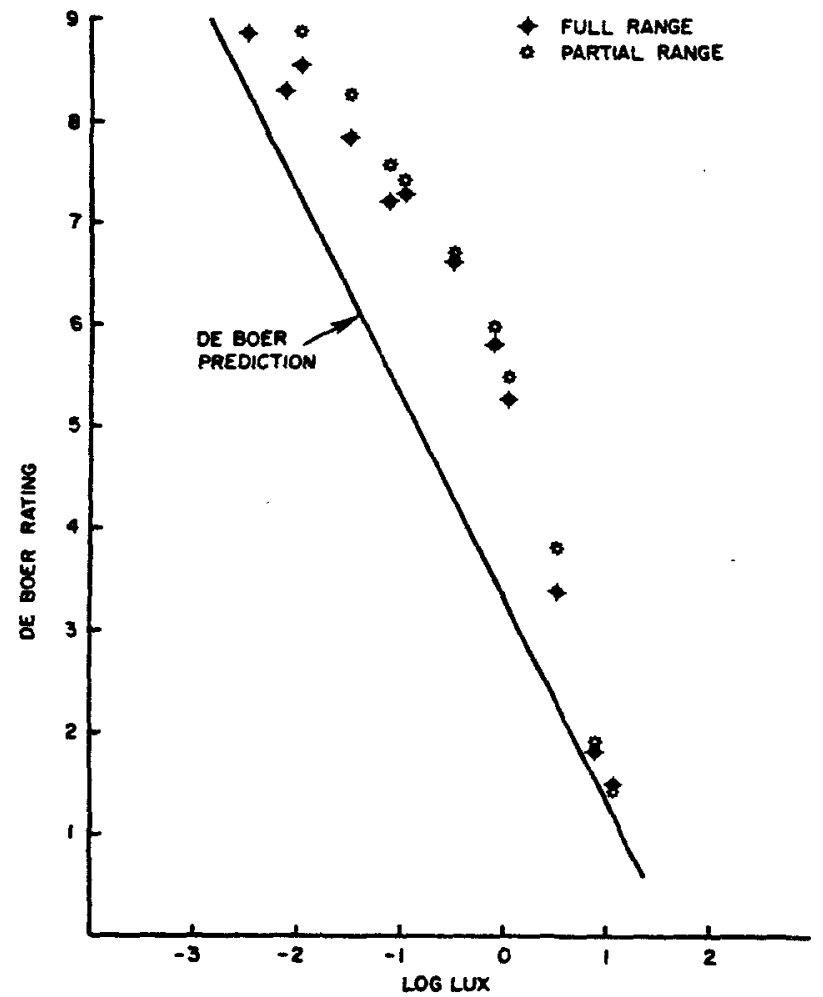

Fig. 13 - Comparison of mean ratings assigned each glare condition in the field compared with prediction based on use of DeBoer equation (01son and Sivak, unpublished)

Unfortunately, as just noted, the results are not in agreement. Given the critical nature of this work to headlamp design, further work is desirable to arrive at more definitive conclusions.

Complicating the glare issue, both from the point of disability and discomfort, is the fact that it is experienced not on $7 y$ from vehicles in the forward field, but from following vehicles, via the rearview mirrors. The problem of rear view mirror glare has been studied in some depth $(69,70,71)$. Briefly summarized, the findings are that both kinds of glare are a problem with the present U.S. low-beam system. Obviously, any increases in intensity will worsen the rear view mirror problem. However, 01son and Sivak (71) argue that this is a problem for which there is a potential solution, namely lower reflectivity for interior and exterior mirrors. However, there is some uncertainty about what this reflectivity should be, especially for outside mirrors.

CONDITIONS DEGRADING LIGHTING SYSTEM PERFORMANCE - Headlamps are designed to provide certain performance levels. Since they are important safety systems, they should come as close to the design performance as possible under normal operating conditions.
Some indication of how well lighting systems actually function under real-world conditions has been provided by Yerrell (72). In this study measurements were taken of the glare and illuminating intensities of a large number of passing vehicles at several sites in Great Britain. These data are reproduced in Figures 14 and 15.

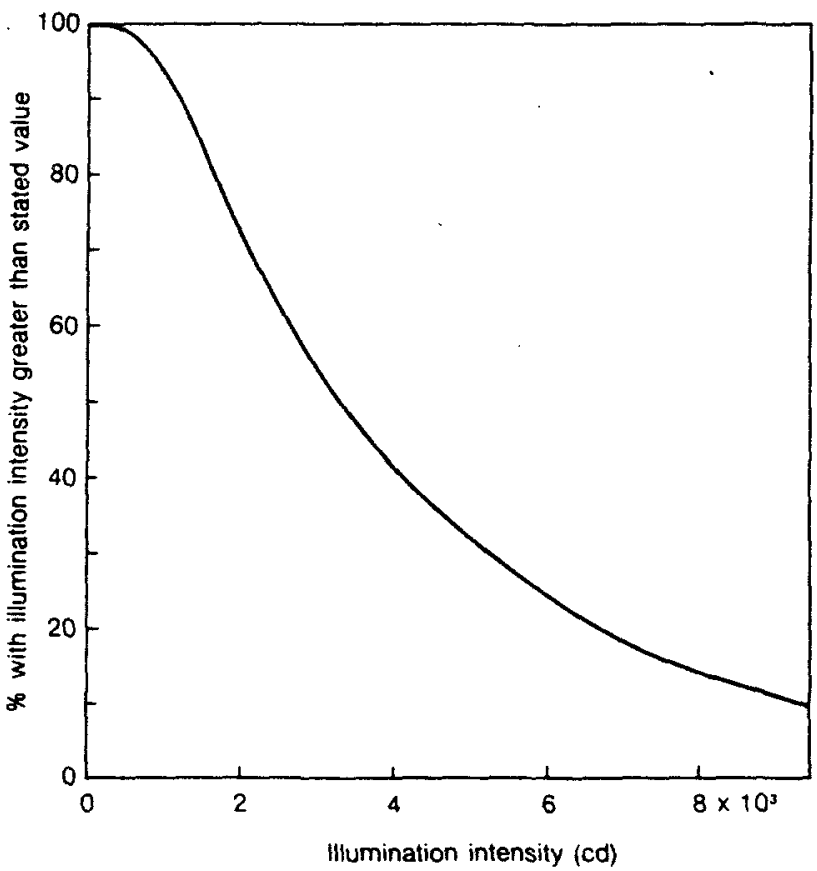

Fig. 14 - Frequency distribution of headlamp illumination intensities in Great Britain(72)

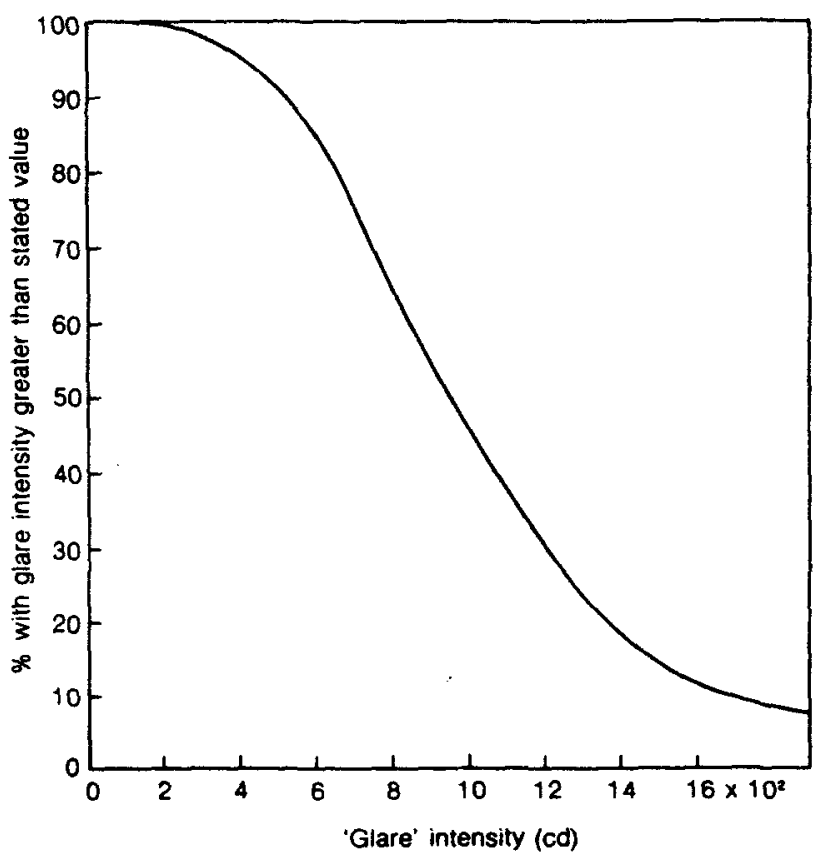

Fig. 15 - Frequency distribution of glare intensities in Great Britain(72) 
Based on -idealized British isocandela diagrams, and the photometric target placements used by Yerrell, the "expected" glare and illumination values were about 1600 and 4000 cd, respectively. The $4000 \mathrm{~cd}$ illumination value falls slightly below the median in Figure 14, indicating it was met by fewer than half of the vehicles in the sample. About $10 \%$ of the measured illuminating intensities were one-quarter or less of the expected value. Glare, as shown in figure 15, was also quite variable, although most measurements (about 85\%) were less than the expected value.

Thus, the available evidence indicates that field headlamp performance varies greatly and that a large fraction of vehicles (about $25 \%$, according to Yerrell) are running with illuminating intensities about one-half or less of levels expected based on design criteria. The reasons for the state of affairs illustrated in Figures 14 and 15 are many and probably not fully known. But, research has been carried out to identify some of the more significant ones. In the next portion of this report these factors will be reviewed, together with other variables affecting system performance not considered in the Yerrell study. Aim - The first systematic work on the aim problem was carried out at the Transportation and Road Research Laboratory in Great Britain $(73,74,75,76)$. They ident ified the major sources of misaim as improper setting by service facilities, changes in the adjusting mechanism, and changes in vehicle attitude due to load.

With the implementation of vehicle inspection programs in several states, headlamp aim was noted as the most common "defect," and misaims $f a r$ in excess of accepted standards were commonly found $(77,78,79,80)$.

Hull et al. (32) measured the extent of misaim in the motor vehicle population by surveying cars in Texas, Missouri, and Kansas. Figure 16 shows low beam vertical aim for Texas, a State with vehicle inspection. Figure 17 shows low beam vertical aim for Kansas and Missouri, states without lamp inspection. As a baseline, SAE standards specify limits of +4 inches at 25 feet. One degree equals 5.2 inches at 25 feet. About $68 \%$ of the lamps were within the SAE limits for low beam vertical aim in Texas compared to $59 \%$ in the other two States.

01 son and Mortimer (81) surveyed the literature to identify the major sources of misaim and estimate their magnitude.

Disregarding vehicle attitude changes, the data indicate that a large fraction of the cars on the road at any given time can be expected to have one or more lamps significantly misaimed. The sources of aim error are summarized in Table 4. Adding to these sources the problem of vehicle load effects, the misaim problem is seen to be very significant.

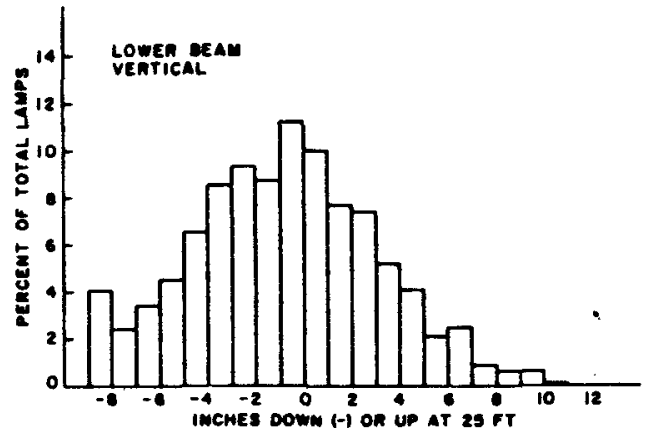

Fig. 16 - Distribution of headlight aim in a vehicle inspection state (Texas) (32)

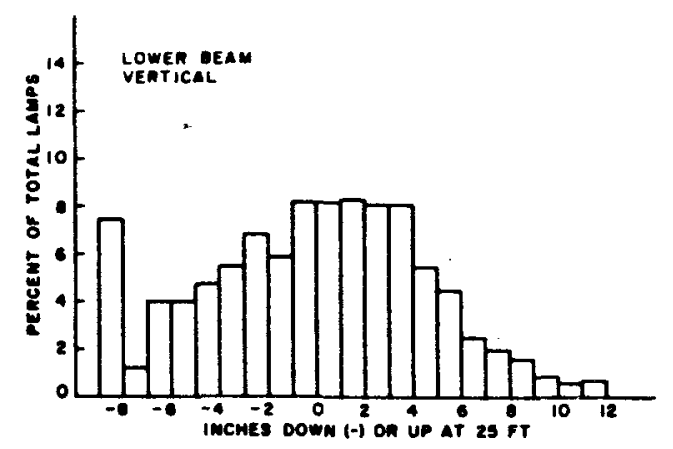

Fig. 17 - Distribution of headlight aim in non inspection states (Kansas and Missouri) (32)

TABLE 4 - Headlamp Aim Variances From All Significant Sources Excluding Load (81)

SOURCE VARIANCE (Degrees)

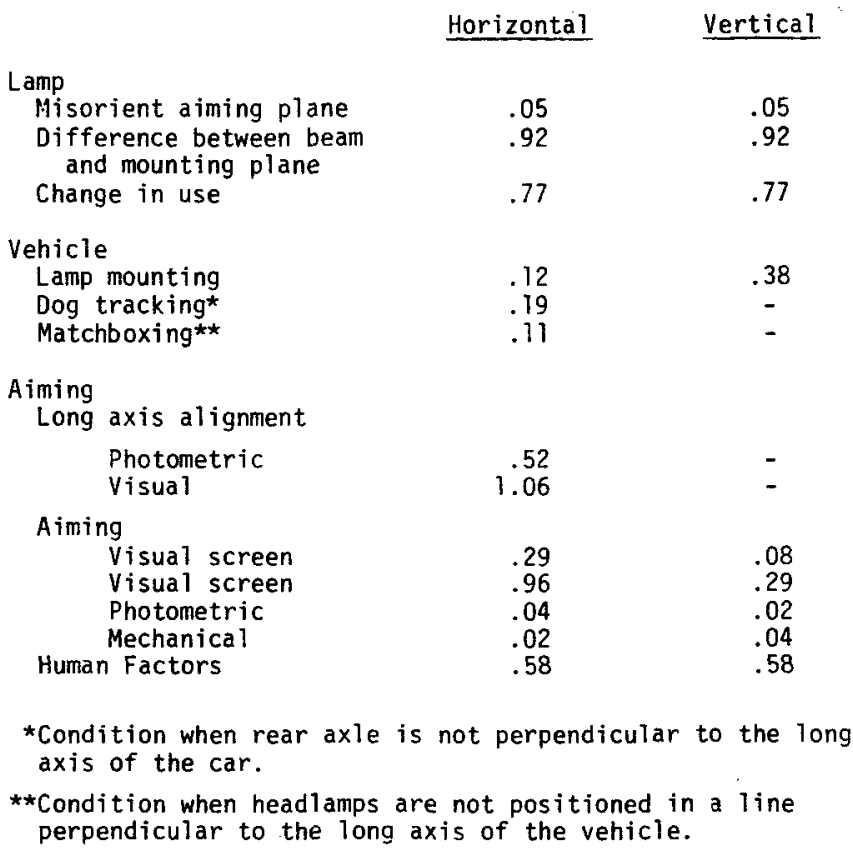


Relatively minor discrepancies between where a lamp is actually aimed and where it was intended to be aimed can produce significant performance changes. By way of illustration, consider Table 5, taken from Hull et al. (32). These data show target detection distances under various beam and misaim conditions. Changes of as little as one degree can result in very large changes in visibility, either due to altered illumination or glare.

TABLE 5 - Visibility Distance As A Function of Aim on Observer And Meeting Cars (32)

\begin{tabular}{|c|c|c|c|}
\hline $\begin{array}{l}\text { Test } \\
\text { No. }\end{array}$ & $\begin{array}{l}\text { Observer's Car } \\
\text { Lamp Aim }\end{array}$ & $\begin{array}{l}\text { Glare Car } \\
\text { Lamp Aim }\end{array}$ & $\begin{array}{l}\text { Target Detection } \\
\text { Distance, ft. }\end{array}$ \\
\hline 1 & $\begin{array}{l}\text { Low beam a imed } \\
\text { correctly }\end{array}$ & No glare care & 397 \\
\hline 2 & $\begin{array}{l}\text { Low beam a imed } \\
\text { correctly }\end{array}$ & $\begin{array}{l}\text { Low beam aimed } \\
\text { correctly. }\end{array}$ & 345 \\
\hline 3 & $\begin{array}{l}\text { Low bean a imed } \\
\text { correctly }\end{array}$ & L.B. $10^{0 U}-10^{\circ}{ }^{\star}$ & 265 \\
\hline 4 & $\begin{array}{l}\text { Low beam aimed } \\
\text { correctly. }\end{array}$ & L.B.1-1/20 U-1-1/20 & 250 \\
\hline $\begin{array}{l}5 \\
6 \\
7 \\
8 \\
9\end{array}$ & $\begin{array}{l}\text { L.B.100-V } \\
\text { L.B.100-V } \\
\text { L.8.10U-V } \\
\text { L.B.10U-V } \\
\text { H.B. aimed } \\
\text { correctlyy }\end{array}$ & $\begin{array}{l}\text { 1.B. correct } \\
\text { Ho glare car } \\
\text { h. B.joU-v } \\
\text { No glare car } \\
\text { No glare ear }\end{array}$ & $\begin{array}{l}208 \\
219 \\
444 \\
697 \\
729\end{array}$ \\
\hline $\begin{array}{l}10 \\
11\end{array}$ & $\begin{array}{l}H . B .1-1 / 2^{\circ} \mathrm{U}-\mathrm{V} \\
\mathrm{H} .8 .1-1 / 2^{\circ} \mathrm{O}-\mathrm{V}\end{array}$ & $\begin{array}{l}\text { No ofare car } \\
\text { No giare car }\end{array}$ & $\begin{array}{l}642 \\
594\end{array}$ \\
\hline
\end{tabular}

"Location referenced to "correct" aim position.

For some misaim problems there are available solutions. For example, vehicle attitude can be controlled with several types of self leveling devices ( 82 ). Other sources of aim error are more difficult to solve.

Dirt - As headlamps accumulate dirt, intensity and seeing distance become degraded. Some indication of the extent of this problem in Sweden has been provided by Rumar (83), whose data are reproduced in Figure 18.

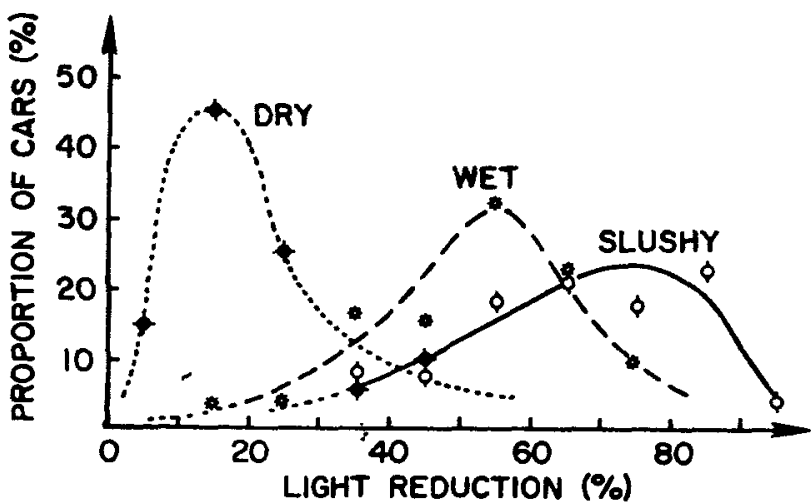

Fig. 18 - Proportion of cars at gas stations having various degrees of light reduction in the central part of the high beam caused by dirt under three road conditions (83)
Detailed measurements of the effect of dirt on photometric performance have been reported by Cox (84). Data from two lamps measured by Cox are shown in Figure 19. The top one was pre-judged "moderately dirty, "the bottom one "very dirty." The moderately dirty condition reduced output on both beams by about $50 \%$. According to Rumar, this is about the least reduction which the drivers $c$ an be expected to notice.
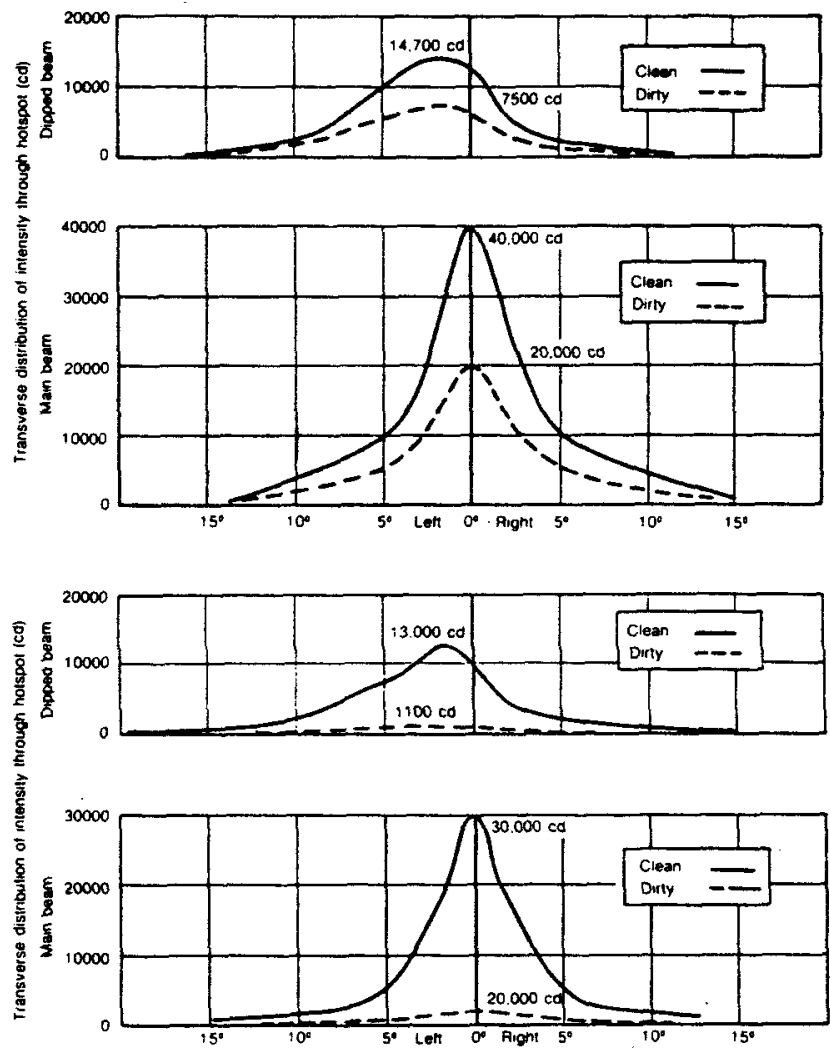

Fig. 19 - Measurements of attenuation due to dirt, taken in the horizontal plane for a lamp judged moderately dirty (top) and very dirty (bottom) (84)

Some indication of what various levels of attenuation mean in terms of loss of visibility has been provided by Rumar (83), whose data are reproduced in Figure 20 . It will be noted that light dirt layers can actually increase visibility distance slightly. This is due to scattering that causes additional illumination to be directed upward. Rumar's data indicate that a $50 \%$ reduction in output would reduce visibility distance by 10-15\%.

Based on the information described, dirt looms as a significant factor in reduced headlamp performance. Several lamp washing/wiping systems have been suggested as solutions and have been marketed in other countries. In the U.S., the use of wiper 
systems is limited because Federal regulations prohibit wiper blades from obstructing light from the lamp. The aiming pads on U.S. lamps make it difficult for wiper blades to "park" of $f$ the lens. Further study to develop the most cost-effective option is needed.

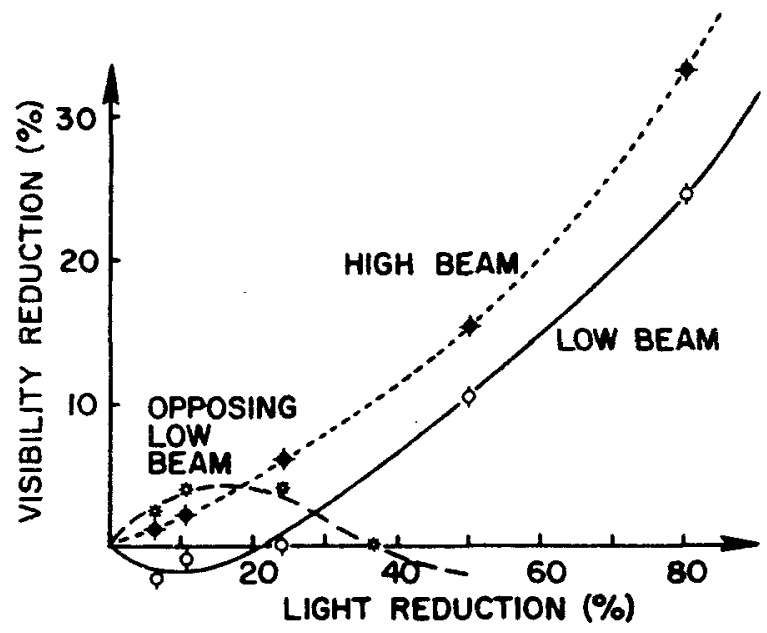

Fig. 20 - Visibility reduction caused by light attenuation due to dirt for three conditions obtained in controlled experiments (83)

Weather - Headlamps must be designed to be minimally affected by adverse atmospheric conditions. Conditions such as fog, snow and rain cause the illumination projected from a headlamp to be scattered. This reduces the illumination actually reaching a target of interest. Some of the illumination is scattered upward, causing the atmosphere between the driver and target to light up, with the result that target contrast is reduced (7).

There have been some efforts to quantify the effects of rain and $f \circ g(7,85,10)$ with a view toward designing lighting systems to be more effective in adverse weather. The results indicate that performance is improved by using lamps which project relatively little

illumination above horizontal, and mounting them as low as possible. Performance is not improved by tinting the lens a yellow color. COMPUTER MODELS - Headlighting is a complex topic, and full-scale lighting studies are expensive to set up and run. The results of these experimental studies are only applicable to the limited conditions of the test. It is thus difficult to evaluate lighting system parameters systematically. For example, experimental results measured under straight, level road meeting situations may not provide a realistic evaluation of performance on curves or when misaimed. Because computer models permit lamp performance to be readily evaluated under many possible conditions, they are valuable tools in lighting research.
The first serious effort to develop a computer seeing distance model was that of Jehu $(86,87)$. This model was written first to simulate a meeting of two cars on a straight-flat road, and then extended to consider curves. The model was used to evaluate various lighting systems in use at that time.

An extensive research effort was undertaken at the University of Michigan in the early 1970's which led to the development of a computer model that computes seeing distance. The model was developed based on extensive field tests (49) and originally applied to meeting situations on flat-straight roads (88). The model was subsequently expanded to include hills and curves (89).

The Unversity of Michigan model has been used extensively over the years for evaluation of alternative lighting systems (90), and as a means of screening candidate lighting systems for later field evaluation $(40,34,35)$.

One problem that was addressed recently using the $U$ of $M$ model is lamp mounting height (71). Current regulations allow mounting heights to vary from a minimum of 24 inches to a maximum of 54 inches. There was concern that the greater heights, common on trucks, caused excessive glare for drivers.

In dealing with this question, the model was run to simulate a number of possible meeting situations using an experimental, high intensity low beam. Some of the data which resulted are shown in Table 6 . This table indicates the gains in visibility distance associated with greater mounting heights, as well as disability and discomfort glare effects. Clearly, greater mounting heights provide both more visibility and glare. Based on this and other analysis, it was concluded that reducing the upper limit on mounting height is unwarranted.

TABLE 6 - Effects of Lamp Mounting Height On Visibility And Glare (71)

\begin{tabular}{|c|c|c|c|c|}
\hline \multirow{2}{*}{$\begin{array}{l}\text { Headl amp } \\
\text { Mount ing He ights } \\
\text { (Inches) }\end{array}$} & \multicolumn{2}{|c|}{$\begin{array}{l}\text { VISIBILITY DISTANCE } \\
\text { (feet) }\end{array}$} & \multicolumn{2}{|c|}{ DISCOMFORT GLARE } \\
\hline & $\begin{array}{l}\text { Maximum } \\
\text { (No Glare) }\end{array}$ & (Max Glare) & $\begin{array}{l}\text { Maximur. } \\
\text { Rating* }\end{array}$ & $\begin{array}{c}\text { Distance at } \\
5.0 \text { or worse } \\
\text { (feet) }\end{array}$ \\
\hline 24 & 292 & 259 & 4.7 & 550 \\
\hline 40 & 315 & 253 & 4.5 & 600 \\
\hline 54 & 338 & 249 & 4.4 & 650 \\
\hline
\end{tabular}

Based on a 9-point scale where 5 * just acceptable, 1 = unbearable, and 9 - just noticeable.

While computer models of the type described above are a considerable help in evaluating certain aspects of beam performance, they are limited in the number of conditions (target type, road topography) that can be 
considered at one time. Since lamp performance varies as a function of conditions tested, the investigator still has the problem of weighting often conflicting result,s to arrive at a meaningful assessment of performance.

Investigators at ford set out to produce a computer model which would provide a comprehensive evaluation. This work has been summarized by Bhise et a1. (10). As a first step the investigators developed a seeing distance model, something like the others which have been described. A simulated standardized test route was then assembled. This route consists of a series of highway sections in the form of environmental parameters which are thought to have an influence on visual performance while driving at night. It includes such factors as pavement, lane line and target reflectance, road geometry, lane configuration, ambient illumination, and glare from fixed lighting and traffic.

When headlighting systems are run in the model, the output is a figure of merit. This figure of merit is the percentage of the distance travelled on the standardized test route during which the seeing distance to pedestrians and pavement lines and the discomfort glare levels experienced by opposing drivers simultaneously meet certain acceptance criteria.

In one analysis using the model, a number of different headlamp systems were compared, including 5-3/4 inch round, 7 -inch round, and 4-x 6-1/2 inch rectanqular US systems; and European Bilux 2-lamp, and Halogen H4, 2-lamp systems. The figures of merit were $74.1,74.0$, $73.9,67.3$, and 71.4 , respectively. The lower ratings for the European systems were attributed to their lower intensity low beam and poorer performance in wet road driving and at speeds over $40 \mathrm{mph}$. However, the European system discomforted from about 2-6\% of the drivers compared to about $10 \%$ for the U.S. beams.

Other analyses conducted with the Ford model have shown that the figure of merit is much more sensitive to environmental variables than headlamp factors. The largest difference between two headlamps had been about 10 percentage points, while different environmental conditions (e.g., road type, road surface condition) have produced differences as large as 60 percentage points. This implies that changing the beam patterns will not have as much effect on system performance as changing roadway environment factors. However, to a large extent this approach is not practical, since certain key variables (e.g., road geometry) cannot really be changed.

Another implication of the mode? is that the intensity of the current U.S. low beam appears to be close to optimum. Some beam patterns did show slight increases in the figure of merit over U.S. low beams. However, it is not clear how much weight to attach to the relatively small differences that are found because the relationship of the figure of merit to real-world accidents is unknown. Thus, to understand the meaning of the figure of merit, it is important to understand the performance criteria built into the model. For example, pedestrian visibility is determined for "unalerted drivers," and discomfort glare is acceptable if the DeBoer glare index is greater than 4 or if it is less than the discomfort glare of a U.S. low beam. Greater figures of merit and larger differences between beam patterns could be achieved if, for example, some pedestrian encounters were with alerted drivers and greater discomfort glare could be tolerated by drivers.

The Ford model is the only approach presently available for evaluating headlights from a systems point of view. It can be of great help in serving as a standardized means of evaluating the relative consequences of changes in headiight parameters. What is needed is general agreement among the lighting research community on the logic and criteria used in calculating the figure of merit.

\section{SUMMARY}

Oriver recognition and detection errors often occur at night because of the obvious visibility degradation that occurs in darkness. Although present-day low beams are adequate for many tasks involving the detection of high contrast objects, they are less than adequate in revealing low contrast objects. The available illumination may not be sufficient to permit drivers to see obstacles, signs, and the direction of the road. The extent of this insufficiency cannot be assessed directly but has been inferred from accident statistics, oriver reports, experimental studies, and analytical evaluations.

In examining the broad accident statistics, nighttime accident rates are found to be three times the day rate. Although some of this difference can be attributed to greater alcohol involvement, fatigue, and young driver problems, inadequate lighting $c$ an be assumed to play a role as well. Even drunk and fatigued drivers might benefit from improved visibility. A number of studies have shown that improved roadway illumination using fixed lighting reduces accidents. However, for the majority of vehicle miles in this country, the only practical means of increasing roadway illumination is to improve headliaht systems. One way to quantify the safety margin drivers have at night is to compare the visibility afforded by headlights with the stopping distance of the car. The measured seeing distance with low beam headlamps varies as a function of many factors, including driver age, target characteristics, beam iniensity, and test methodology. For pedestrian type targets, seeing distance on typical U.S. low beams has been shown to vary from about 30 meters $(99 \mathrm{ft})$ to 120 meters $(396 \mathrm{ft})$. In meeting situations, the seeing distance ranges from about 25 to 80 meters (83-264 feet). 
The maximum safe speeds for these stopping distances $c$ an be calculated for various combinations of road friction and assumed driver perception reaction time. For example, on a dry pavement the maximum speed for a 396 foot stopping distance is about $55 \mathrm{mph}$, assuming a 2.5 second driver reaction time. In opposing traffic the 264 foot stopping. distance corresponds to about a $42 \mathrm{mph}$ safe speed. Since these maximum visibility distances are likely to be considerably less in the real world, the margin of safety for many drivers will be negative. For example, the 83 foot visibility distance measured in some tests translates to about $28 \mathrm{mph}$ under the most ideal driving conditions (i.e., dry pavement and one second driver perception reaction time).

The problem of nighttime driving has been recognized for many years by researchers who have sought to develop improved headlighting systems. Progress has been slow because of the difficulty of resolving the many tradeoffs involved with headlight design. The primary tradeoff involves illuminating intensity versus glare intensity. Seeing distance in open-road driving can be increased somewhat by simply increasing the lamp intensity; but in vehicle meeting situations the number of drivers complaining about glare would also increase and seeing distance would be impaired. The polarized headlighting system had been proposed as a solution to this tradeoff. However, cost and implementation problems caused researchers to seek simpler and more practical approaches.

The research on improving the low beam has concentrated on how to change beam intensity and distribution. Such an approach has shown that only relatively small increases in visibility can be made because of the limitations of current lamp design and manufacturing techniques and because of the laws of physics and response of the human visual system. However, even small increases in visibility are important to help counter the many environmental, driver, and vehicle factors that degrade low beam performance.

Some of the vehicle design factors that can reduce driver visibility have become more significant in recent years because of basic changes in the characteristics of the vehicle fleet. Although basic low beam technology has not changed significantly since the 1950 's, the vehicle fleet has changed in a number of ways that can reduce headlamp performance including 1) increased use of tinted windshields, 2) lower lamp mounting height in passenger cars, and 3) lower driver eye height. In addition, the increased percentage of smaller cars raises the question of whether there is increased lamp susceptibility to misaim due to vehicle loading. Currently, a number of proposals have been advanced which would significantly change the technology of lamp construction. While these technologies may offer some styling and fuel economy benefits to consumers, their long term road illumination performance is uncertain.
Headlamp performance is also affected by the extent and nature of the limit conditions imposed by various environmental and driver factors. For example, weather and road topography have been shown to influence headlamp illumination. Also, the increasing proportion of older drivers could further reduce the level of visibility provided by headl amps.

While each of the above factors may have a relatively small effect on nighttime visibility when considered individually, the combined action of all of them suggest that the need to maintain and improve low beam performance is more critical than ever.

One of the ways to evaluate the effects of these conditions on headlamp performance is through the use of a figure of merit such as that developed by Bhise et al. The figure of merit provides a systematic and comprehensive evaluation of the many interacting factors influencing night driving safety.

One of the factors affecting the figure of merit is discomfort glare. Discomfort glare is an issue which divides American and European lighting engineers. There are relatively few studies on discomfort glare. Some of these, especially those conducted in laboratory settings, suggest we are at the limit for glare. Others, especially those conducted in field settings, indicate further increase in glare may be possible. And there are other data that indicate that people's judgment of what is objectionable varies depending on the context in which the judgment is made.

Other components of the figure of merit are performance degrading factors such as misaim and dirt. However, existing data on the extent and nature of these factors is not up to date for the current U.S. vehicle fleet.

AN AGENDA FOR FUTURE ATTENTION - The

information discussed in this literature review suggests a number of problem areas that need further attention:

1) Because headlamp performance has been shown to vary as a function of test conditions, a standardized approach to evaluation of headlamp performance needs to be developed. This approach should be based on the performance of headlamps under the hazardous conditions that can lead to accidents. The figure of merit technique used in the Ford model can be employed as a basis for such evaluations. A figure of merit for headlamp system performance $c$ an be used to evaluate the safety implications of changes to the vehicle fleet that affect nighttime vision. The components of the figure of merit developed by Ford comprise many of the driver, vehicle, environment, and hazard characteristics associated with accidents caused by inadequate nighttime visibility. A review of the 
model is needed to assess the model components and performance criteria that affect the figure of merit value. It would also be worthwhile to explore the possibility of relating changes in the figure of merit to accident rates for various subfleets even though such a task may prove 0 be very difficult.

2) Because the most recent data on the extent and nature of headlamp misaim is over 10 years old, a survey of current aim practices is needed. This survey will help to evaluate the seriousness of the aim problem and identify the sources of aim variance that need to be remedied. The extent of the headlamp dirt problem also needs to be surveyed for the same reasons.

3) Because of the significance of discomfort glare to the evaluation of headlamps, further work is needed to increase our knowledge of the subject. Additional testing under actual field conditions with a broad range of subjects is required. Also, evaluations of the exposure of drivers to different glare levels is needed to determine frequency of exposure to glare and the intensity of the exposure. Such information can be used in assessing the tradeoffs between a beam pattern which might provide intense glare in relatively few meeting situations versus a lamp which provides lower glare levels in a large number of meetings.

4) Because many new technologies for headlamp construction are being developed, a better understanding of their potential advantages and disadvantages is needed.

From a broader perspective, a better understanding of the visibility conditions associated with accidents needs to be developed. A knowledge of the visibility characteristics of struck obstacles or pedestrians or road delineation could help pinpoint the major safety problems of nighttime driving and provide a better understanding of appropriate countermeasures. Given what we know now about the limited seeing distance available to drivers, it might also be worthwhile to try to answer the question of why drivers maintain speeds so far above their ability to stop or maneuver to avoid a collision.

\section{REFERENCES}

1. Gallagher, V.P. and Janoff, M.S. Interaction between fixed and vehicular illumination systems. Frank in Institute Research Laboratories, Philadelphia, Pa, Report No. F-C2873/ FHWA-RD-72-51, July, 1972
2. Scott, P.P. The relationship between road lighting quality and accident frequency. The Transport and Road Research Laboratory, Digest LR929, 1980.

3. Merritt, J.0., Helander, M., Abrams, C., and Miller, J.C. The effect of wide-angle headlight illumination on driver performance. Human Factors Research Inc. Contract No. DOT-HS-7-01724, June 1982

4. Treat, J.R. and Romberg, R.A. Tri-levelstudy: Modification. Task i: Final report on potential benefits of various improvements in vehicle systems preventing accidents or reducing their severity. Final report. Indiana University, Bloomington, Institute for Research in Public Safety, Report No. DOT-HS-805 094, 1977.

5. Hale, A. and Blomberg, R.D. "Conspicuity for Pedestrians and Bicyclists Task 2 Interim Report: Operational Definition of Conspicuity and Accident Analyses" NHTSA Contract, DTNH22-80-C-07052, February, 1982. 6. Burger, W.J., Smith, R.L., Queen, J.E., and Slack, G.B. Accident and near accident causation: The contribution of automobile design characteristics. Dunlap and Associates, LaJolla, Cal ifornia, Contract No. DOT-HS-802-714, 1977.

7. Koth, B.W., McCunney, W.D., Dverk, D.P., Janoff, M.S., and Freedman, M. Vehicle Fog Lighting: An Analytical Evaluation. Frank in Institute Research Laboratory. Report DOT-HS-803-442, March 1978.

8. Haghighi-Talab, D., "An

Investigation into the Relationship Between Rainfall and Road Accident Frequencies on Two Cities" Accident Analys is and Prevention - Vol 5, No. 4, 1973 pp 345-349.

9. OECD Road Research Group, "Adverse Weather, Reduced Visibility, and Road Safety" The Organization for Economic Cooperation and Development, August 1976.

10. Bhise, V.D., Farker, E.I., Saunby, C.S., Troell, G.M., Walunas, J.B., and Bernstein, A. Modeling Vision With Headlights In a Systems Context. Ford Motor Company, Automotive Safety Office, Dearborn, Michigan. Society of Automotive Engineers, International Automotive Engineering Congress and Exposition, 28 Feb-4 March 1977, Report No. SAE 770238.

11. Devaux, P. Unified European Passing Beam and Yellow Light. International Road Safety and Traffic Review, 4, 1956, 33-39. 12. Christie, A.W., Ashwood, J.E., and Symons, R.D.H.. Visual Acuity In Yellow Headlights. Road Research Laboratory, Crowthorne, England, Report No. RRL Report LR 156, 1968.

13. Schreuder, D.A. White or yellow light for Vehicle Headlamps? Institute for Road Safety Research SWOV, Voorburg (The Netherlands). Report No. 1976-2E, 1976.

14. Lee, R.L. and Scott, D.P. "Driver Eye Height and Vehicle Sales Trends" Federal Highway Administration, Office of Highway Safety, January, 1981. 
15. 01son, P.L., Jorgeson, C.M., Sturgis, S.P., Thomas, J.K., and Domas, P.A. Factors Influencing the Effectiveness of Automotive Rear Lighting Systems. The Highway Safety Research Institute, University of Michigan, Report No. UM-HSRI-HF-75-4, October 1975.

16. Pulling, N.H., Wolf, E., Sturgis, S.,Vaillancourt, D.R., and Dolliver, J.J., "Headlight Glare Resistance and Driver Age" Human Factors 1980, 22(1), 103-112

17. Sturges, S. and Osgood, 0 . "Measuring the Quality of Drivers' Night Vision" Proceedings of the Human Factors Society 25th Annual Meeting - 1981

18. Hauser, E.W., Moore, R.P., and Homeyer, P.G. Macklenburg County Drinking/Oriving Survey, 1970. Research Triangle Park, North Carolina. Research Triangle Institute, Project No. SU-582-4, January 1971.

19. Nelson, J.H. Design and use of headlamp meeting beams. Proceedings of the Institute of Mechanical Engineers, Auto Division. 1954-55, 3, 100-107, 117-129.

20. Moore, R.L. Headlight design. Ergonomics, 1958, I(2), 163-176.

21. Roper, $\bar{V}$.J. Four headlamps for better seeing. Traffic Engineering, 1957, 27, $171-175$.

22. Devaux, $P$. State-of-the-art signaling and lighting. International Commission on Illumination (France). 1970 International Automobile Safety Conference Compendium, SAE, Report No. SAE 700386, 1970, $555-580$

23. Kilgour, T.R. Some results of cooperative vehicle lighting research.

Chrysler Corporation. National Research Council, Highway Research Board Bulletin, 1960, $255,92-100$

24. Meese, G.E. Vehicular Lighting systems fortwo-lane rural highways. General Electric Company, Cleveland, Ohio. Workshop on Highway Visibility, Highway Research Board, Committee on Visibility, 1972.

25. DeBoer, J.B. A "duplo" headlight with asymmetric passing beam. Light and Light ing, 1955, XLVIII (4).

26. DeBoer, J.B. Progress in automobile lighting as a result of international visibility tests. Road Safety and Traffic Review. Winter, 1956, 18-23.

27. Jones, K.J. Comments on vehicle lighting following international visibility tests. Joseph Lucas (Electrical) Ltd., Birmingham, England. International Road Safety and Traffic Review, pp. 24-25,41, Winter 1956

28. Bailly, F., Cibie, P., and Devaux, $P$. The use of iodine lamps in car headlights. NNHZWF Motor Industry Research Association. Lindley, England. Ingenieurs de 1' Auto, June. $1963,36(6), 317-330$.

29. Roper, V.J. and Morgenstern, L.A. Quartz-iodine headlamps slated for European debut. General Electric Company. Cleveland, Miniature Lamp Department, Ohio, SAE Journal, $1964,72(6), 30-35$.
30. Ehrhardt, R.Q. Halogen sealed beam head-lamps. General Electric Company, Miniature Lamp Department, Cleveland, Onio. Society of Automotive Engineers Congress and Exposition, 26 Feb- 2 March 1979, Report No. SAE 790200 .

31. Zaccherini, F. and Thulin, A. A survey of motor vehicle headlights. Stockholm, P66-332, Final Report, Lab C 12, 1969.

32. Hu 11, R.W., Hemion, R.H., and Cadena, D.G. Guidelines for improving the stability of headlamp aim. Final report. Southwest Research Institute, San Antonio, Texas, Report No. AR829/ DOT/HS 800 739, August 1972.

33. Roper, V.J. and Meese, G.E. More light on the headlighting problem. General Glectric Co., Miniature Lamp Department, Cleveland, Ohio, 1963.

34. Sturgis, S.P. Motorcycle headlighting research. University of Michigan Highway Safety Research Institute, Report No. UM-HSRI-HF-75-3, Contract No. DOT-HS-4-00907, August 1975.

35. 01son, P.L. and Abrams, R.A. Improved motorcycle and moped headlamps. University of Michigan Highway Safety Research Institute, Report No. 82-18, May 1982.

36. Adler, B. and Lunenfeld, $H$.

Three-beam headlight evaluation. Airborne Instruments Laboratory, Deer Park, N.Y. Report No. 0276-1/D0T-HS-800 844, April 1973.

37. Bhise, V.0., McMahan, P.B., and Farber, E.I. Predicting target-detection distance with headlights. Transportation Research Record, 1976, No. 611, 1-16.

38. DeBoer, J.B. and Morasz, W. Berechnung der Schweite aus der Lichtverteilung von Automobilescheinwerfern. N.V. Philips' Gloeilampenfabrieken, Light-Technical

Laboratory, Eindhoven, Netherlands,

Lichttechnik, 1956, 8(10), 433-437.

39. Graf, C.P. and Krebs, M.J. Headlight factors and nighttime vision. Final report. Honeywe 11. Inc., Systems and Research Division, Minneapolis. Minn. Report No.

76SRC13/D0T-HS-802 102, November 1976.

40. Halstead-Nussloch, R., 01son, P.L. Burgess, W.T., Flannagan, M.J., and Sivak, M. Evaluation of the feasibility of a single-beam headlighting system. Final report. Highway Safety Research Institute, Ann Arbor, Michigan, Report No. UM-HSRI-79-91, December 1979.

41. Helmers, G. and Rumar, K. Obstacle visibility in rural night driving as related to reflective qualities of the road surface. Uppsala University, Department of Psychology, Sweden. Report No. 150, 1974.

42. Helmers, G. and Rumar, K. High beam intensity and obstacle visibility. Uppsala University, Department of Psychology, Sweden. Report No. 150, 1974.

43. Hemion, R.H. Interchangeability of vehicle headlamps. Southwest Research Inst itute, Report DOT HS-800966, August 30, 1973. 
44. Hemion, R.H. and Hul1, R.W. Optimum two-lamp headlighting system. Final report. Southwest Research Institute, San Antonio, Texas, Report No. AR-891/D0T-800 890, July 1973.

45. Johansson, $G$. and Rumar, $K$.

Available braking distances in night driving. Uppsala University, Department of Psychology, Sweden, Report No. 13, November 1963.

46. Johansson, G., Bergstorm, S.S., Jansson, G., Ottander, C., Rumar, K., and Ornberg, G. Visibility distances in simulated night driving conditions with full and dipped headlights. Uppsala University, Psychological Laboratory, Sweden. Ergonomics, 1963, 6(2), $171-179$.

47. Kazenmaier, A. Internationale Vergleichsversuche and Abblendlichtern von Automobilescheinwerfern des amerikanischen und europaischen Typs. (International comparative experiments with the meeting beams of American and European motor-car headiights.) Robert Bosch GmbH, Stuttgart, Germany. Deutsche Kraftfahrtforschung und Strassenverkenhrstechnik, Heft 94, 1956. 48. Lindae, G. Licht am Fahrzeug - ein Beitrag zur Verkehrssicherheit. Robert Bosch GmgH, Stuttgart, Germany. ATZ, 1962, (64 (5), 152-158.

49. Mortimer, R.G. and 01son, P.L. Development and use of driving tests to evaluate headlamp beams. Final report. Highway Safety Research Institute, Ann Arbor, Michigan, Report No. UM-HSRI-HF-74-14, March 1974.

50. Roper, V.J. and Howard, E.A. Seeing with motorcar headlamps. Illumination Engineering, 1938, 33, 412-438.

51. Roper V. and Scott, K.D. Silhouette seeing with motor car headlamps. General Electric Company, Cleveland, Nela Park Engineering Department, Ohio. Illuminating Engineering Society Transactions, 1939, 34, 1073-1084

52. Rumar, K. Visible distances in night driving with misaligned meeting dipped headlights. Uppsala University, Department of Psychology, Uppsala, Sweden. August 1965.

53. Rumar, K. Halogen and conventional continental European headlights; a comparison of visibility distances. Uppsala University, Department of Psychology, Sweden, 1970.

54. Rumar, K., Helmers, G., Thore 11, M. Obstacle visibility with European halogen $\mathrm{H}_{4}$ and American sealed beam headlights. Uppsala University, Traffic Safety Research Group, Sweden, Report No. 133, 1973

55. Schmidt-Clausen, H.J. The visibility distance of a car-driver in driving situation. Society of Automotive Engineers, International Congress and Exposition, February 22-26, 1982 , Detroit, MI. Report No. SAE 820416.

56. Webster, L.A. and Yeatman, F.R. An investigation of headlight glare as related to lateral separation of vehicles. Illinois University, Engineering Experiment Station, Urbana, Report No. Engineering Experiment Station Bullet in 496, 1968.
57. Zechnall, R. Influence of light distribution of headlamps on seeing distances. Ingelstam, E., ed., Light ing Problems in Highway Traffic, MacMillan Co., 1963, 53-72.

58. Campbel1, W.F., "Automobile Stopping Distances for Judging Headlight Performance" National Research Council Canada, LTR-ST 595, February, 1973.

59. Huculak, P. Ascertaining the effects of atmospheric factors during visual detection experiments in automobile headlighting. National Research Council, Ottawa, National Aeronautical Establishment (Canada), Report No. LTR-ST-987, May 1978a.

60. Hul1, R.W., Hemion, R.H., Cadena, D.G. and Dia1, B.C., "Vehicle Forward Lighting Performance and Inspection Requirements "NHTSA Contract FH-11-7342, July 1971.

61. Cole, B.L. Some observations on disability glare. In: Proceedings of Glare Seminar, Austrailian Road Research Board, Victoria, 1977

62. Holladay, L.L. Action of a light-source in the field of view in lowering visibility. Journal of the Optical Society of America. Vol, 14, 1927, 1-9.

63. Itiles, W.S. The effect of glare on the brightness difference threshold.

Proceedings of the Royal Society, B104, 1929, $322-250$

64. Grime, $C$. The performance of head-lamp meeting beams. Institution of Mechanical Engineers. Automohile Division. Proceedings. 1954-55, 3, 108-129.

65. DeBoer, J.B. Quality criteria for the passing beam of headlights. Paper presented at the CTB meeting in Walldorf, West Germany, September 1973.

66. Schmidt-Clausen, H.J. and Bindels, J.T.H., Assessment of discomfort glare in motor vehicle lighting. Lighting Research and Technology, 1974. 6(2), 79-88.

67. Mortimer, R.G. and 01son, P.L. Evaluation of meeting beams by field tests and computer evaluation. Final report. Highway Safety Research Institute, Ann Arbor.

Michigan. Report No. UM-HSRI-HF-74-27, December 1974.

68. Lulla, A.B. and Bennett, C.A. Discomfort glare: range effects. Journal of the Illumination Engineering Society. 10(2), January 1981, 74-80.

69. Miller, N.D., Baumgardner, D., and Mortimer, R.G. An evaluation of glare in nighttime driving caused by headlights reflected from rearview mirrors. Society of Automotive Engineers, Automobile Engineering Meeting, October 21-25, 1974, Toronto, Canada. Report No. SAE 740962.

70. Rowland, G.E., Moretti, E.S., and Patton, M.L., Evaluation of glare from following vehicle headlights. Final report. Rowland and Company, Inc., Haddonfield, N.J., Report No. DOT/HS 805837 , January 1981. 
71. 01son, P.L. and Sivak, M. Improved low-beam photometrics. University of Michigan Highway Safety Research Institute, Report No. UM-HSR I-81-4, February 1981.

72. Yerrel1, J.S. Headlamp intensities in Europe and Britain. Road Research Laboratory, Crowthorne (England), Report No. RRL LR 383, 1971.

73. Jehu, V.J. Seeing with foglamps. Light and Lighting, May 1953, 46(5), 174-178.

74. Jehu, V.J. Headlight setting. Part 1. An investigation of commercial testers. Part II. - An improved headlight tester. Automobile Engineer, Part 1, April 1954, 44(4) 159-164. Part II: 44(5), May 1954, 213-215.

75. Jehu, V.J. Vehicle headlamp testing. Road Research Laboratory, Crowthorne (England), 1958.

76. Harris, A.J. The meeting beams of headlights; effects of deterioration and misaim. Illuminating Engineering Society Transactions, 18(8), 1953, 207-220

T7. Finch, D.M., Dunlop, D.R., and Collins, D.M. Headlamp survey program. University of California, Berkeley. Report No. HP-47, September 1969.

78. Finch, D.M. Controlling headlamp aim. California University, Berkeley, College of Engineering, 1970.

79. Heath, W.M. Problems in passenger car headlamp aim. Society of Automotive Engineers, International Automotive Engineering Congress, Jan. 8-12, 1973, Detroit, Michigan, Report No. SAE 730009.

80. Terry, R.M. Automotive headlamp aiming - intentions and results. Society of Automotive Engineers, International Automotive Engineering Congress, January 8-12, 1973, Detroit, MI, Report No. SAE 730007.

81. 0ison, P.L. and Mortimer, R.G. Analys is of sources of error in headlamp aim. Automotive Engineering Congress, February 25 March 1, 1974, Detroit, MI, Report No. SAE 740312 .
82. Yerre11, J.S. The performance of two self-levelling headlamp systems. Road Research Laboratory, Crowthorne (England), Report No. RRL LR 378, 1971.

83. Rumar, $K$. Dirty headlights frequency and visibility distances. Uppsala University, Department of Psychology, Sweden, 1970.

84. Cox, N.T. The effect of dirt on vehicle headlamp performance. Report No. RRL Report LR 240, Road Research Laboratory, Crowthorne (England).

85: Jehu, V.J. A survey of vehicle headlights. Illuminating Engineering Society Transactions, 1953, 18(9), 249-259.

86. Jehu, V.J. A method of evaluating seeing distances on a straight road for vehicle meeting beams. Road Research Laboratory, Crowthorne, England. Illuminating Engineering Society Transactions, 1955, 20(2), 57-67.

87. Jehu, V.J. A method of evaluating seeing distances on a curved road and its application to headlight beams in England. Illuminating Engineering Society. London. Transactions, 1957, 22(3), 69-83.

88. Mortimer, R.G. and Becker, J.M. Development of a computer simulation to predict the visibility distance provided by headlamp beams. Highway Safety Research Institute, Ann Arbor, Michigan, Report No. UM-HSRI-HF-73-15, July ig73a.

89. Mortimer, R.G. and Becker, J.M. Computer simulation evaluation of current U.S. and European headlamp meeting beams, and a proposed mid beam. Highway Safety Research Institute, Ann Arbor, Michigan. Automotive Engineering Congress, 25 Feb-1 March 1974, Detroit, Michigan. Report No. SAE 740311 . 90. Mortimer, R.G. and Becker, J.M. Development of a computer simulation to predict the visibility distance provided by headlamp beams. Highway Safety Research Institute, Ann Arbor, Michigan, Report No. UM-HSRI-HF-TM-73-4, May $1973 \mathrm{~b}$.

The views expressed in this paper are those of the authors and not necessarily those of the National Highway Traffic Safety Administration 